JOB CRAFTING AND THE MODERATING ROLE OF A GROWTH MINDSET: A PRETEST-POSTTEST STUDY DESIGN

\author{
A Thesis submitted to the faculty of \\ San Francisco State University \\ In partial fulfillment of \\ the requirements for \\ the Degree \\ Master of Science \\ In \\ Psychology: Industrial/Organizational Psychology
}

by

Aline Ayres dos Santos Mello

San Francisco, California

May 2020 
Copyright by

Aline Ayres dos Santos Mello

2020 


\section{CERTIFICATION OF APPROVAL}

I certify that I have read Job Crafting and The Moderating Role of a Growth Mindset: a pretest-posttest study design by Aline Ayres dos Santos Mello, and that in my opinion this work meets the criteria for approving a thesis submitted in partial fulfillment of the requirement for the degree Master of Science in Psychology: Industrial/Organizational Psychology at San Francisco State University.

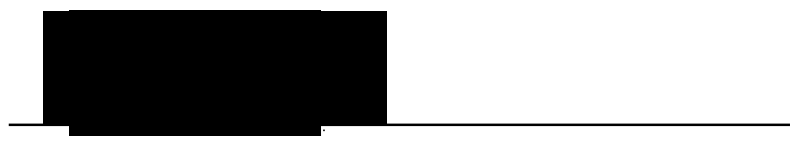

Kevin J Eschleman, Ph.D.

Associate Professor

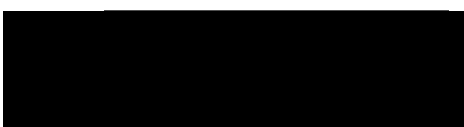

Christian W Wright, Ph.D.

Professor 


\title{
JOB CRAFTING AND THE MODERATING ROLE OF A GROWTH MINDSET: A PRETEST-POSTTEST STUDY DESIGN
}

\author{
Aline Ayres dos Santos Mello \\ San Francisco, California
}

2020

This study examines job crafting as a strategy through which employees may learn and adapt to the needs of their ever-changing jobs. The current study uses a quasi-experimental design to investigate the effect of a job crafting intervention on stimulating job crafting behaviors in participants. It also tests the extent to which this relationship is moderated by individuals' mindset. To do so, undergraduate students $(n=275)$ received an online job crafting intervention, after which they worked towards self-set crafting goals for a period of 30 days. Pre-post comparison tests for the experimental group showed no main effect of the job crafting intervention for any of the job crafting variables. However, a growth mindset was found to moderate the relationship between job crafting and job crafting behaviors; yet, in the opposite direction than predicted. Taken together, the findings of this study indicate that a job crafting intervention may be an effective way to stimulate changes in job crafting behaviors, however, its use may be successful for some, but not others. Implications of these findings and future directions are discussed.

I certify that the Abstract is a correct representation of the content of this thesis.

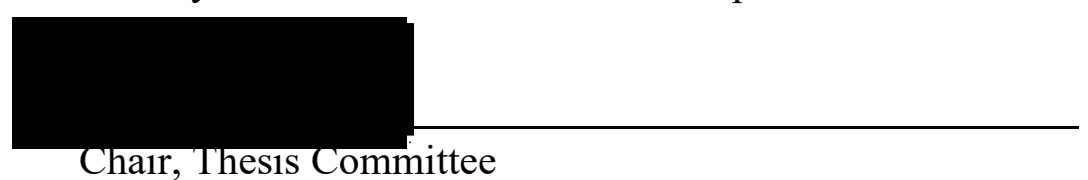




\section{TABLE OF CONTENTS}

List of Tables ................................................................................................. vi

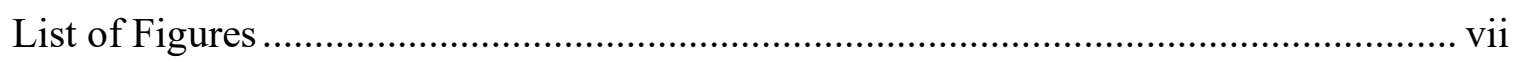

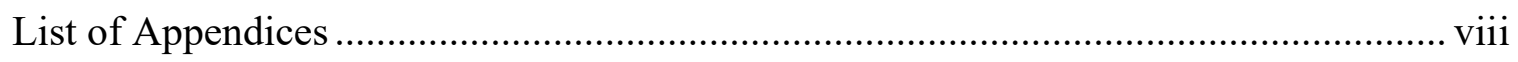

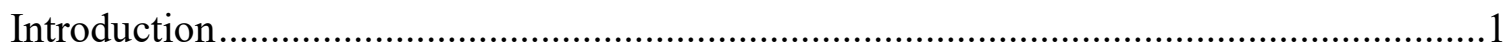

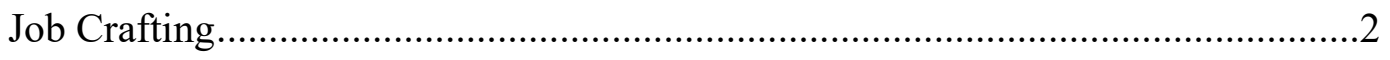

Job Crafting Intervention ....................................................................

Job Crafting and Growth Mindset............................................................

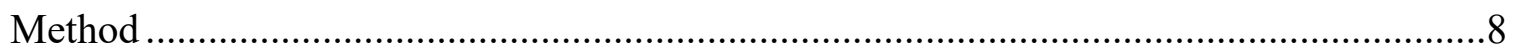

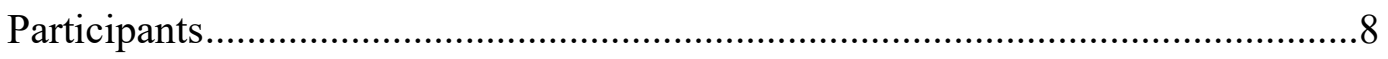

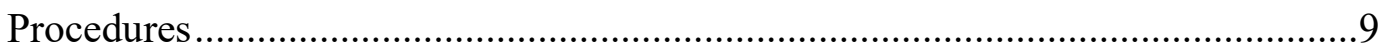

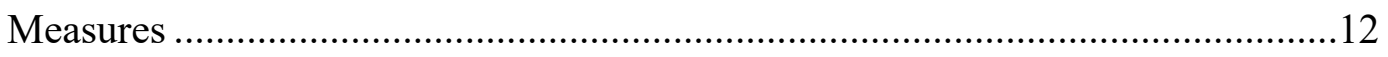

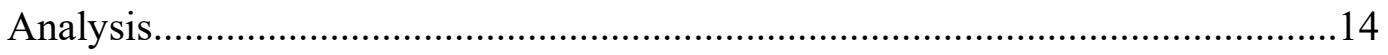

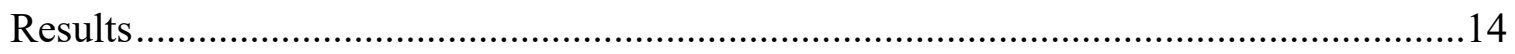

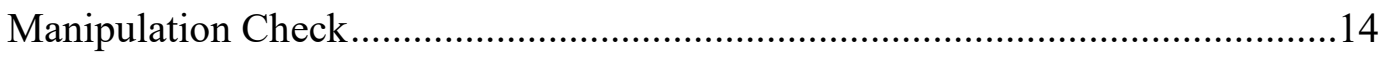

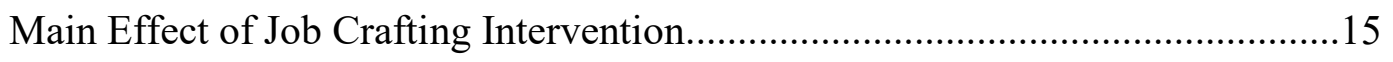

Moderating Effect of Growth Mindset on Job Crafting Intervention ...................16

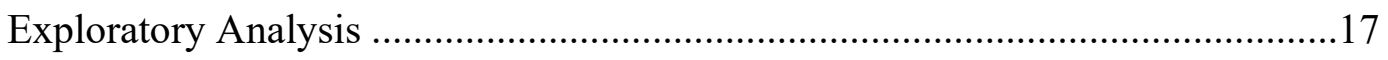

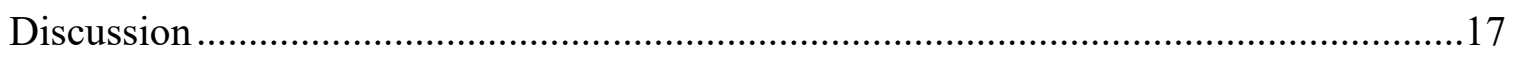

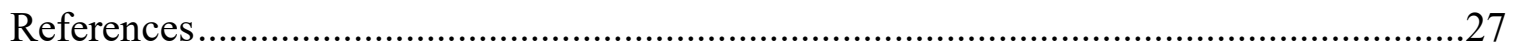

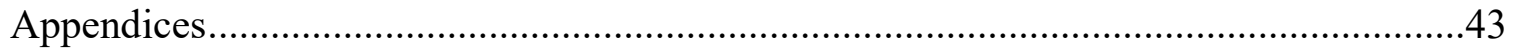




\section{LIST OF TABLES}

Table Page

1. Descriptive Statistics and Correlations for Study Variables..........................30

2. Mean scores and repeated measures ANOVAs for job crafting variables within

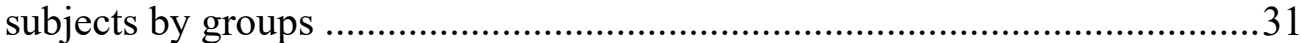




\section{LIST OF FIGURES}

Figures

1. Hypotheses Testing Model........................................ 32

2. Moderation Effect of Growth Mindset on Overall Crafting for Course B.....33

3. Moderation Effect of Growth Mindset on Cognitive Crafting for Course B...34

4. Moderation Effect of Growth Mindset on Skill Crafting for Course B........35

5. Moderation Effect of Growth Mindset on Task Crafting for Course B........36

6. Moderation Effect of Growth Mindset on Relational Crafting for Course B...37

7. Moderation Effect of Growth Mindset on Overall Crafting for Course A......38

8. Moderation Effect of Growth Mindset on Cognitive Crafting for Course A...39

9. Moderation Effect of Growth Mindset on Skill Crafting for Course A........40

10. Moderation Effect of Growth Mindset on Task Crafting for Course A........41

11. Moderation Effect of Growth Mindset on Relational Crafting for Course A...42 


\section{LIST OF APPENDICES}

$\begin{array}{lll}\text { Appendix } & \text { Page }\end{array}$

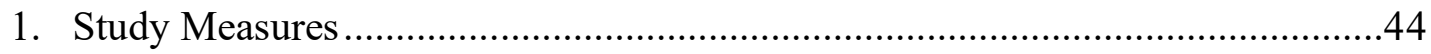

2. Job Crafting Exercise Worksheet(Course B)......................................................47

3. Job Crafting Action Plan Workshop Assignment (Course B)...............................53

4. Job Crafting Action Plan Video Assignment (Course A).......................................55 
The growing use of new technologies in the workplace could have drastic implications for how organizations and employees function. In fact, advances in technology are making it possible for machines to not only do things that we thought only humans could do, but also to do them at a superhuman level of performance (Grace et al., 2018). Accordingly, organizations will continue to use technologies in order to complete tasks traditionally done by human beings. For instance, companies expect a significant shift in the work balance between humans and machines when it comes to existing tasks between the years 2018 and 2025 . In 2018, an average of $71 \%$ of total task hours across 12 industries were performed by humans, compared to $29 \%$ by machines. By 2025 this average is expected to have shifted significantly, to $48 \%$ task hours performed by humans and $52 \%$ by machines (World Economic Forum, 2018).

These changes will directly impact the workers themselves, as different skills will be needed to perform these new types of jobs (WEF, 2018). Consequently, some of the organizations' main concerns regarding their workforce in the future include employees who do not upgrade skills fast enough, or are not sufficiently adaptable transitioning to new forms of work, and lack the requisite technical skills to do so (Bughin et al., 2018). However, nearly a quarter of companies are either undecided or unlikely to pursue the retraining of existing employees, and two-thirds expect workers to adapt and pick up skills in the course of their changing jobs (WEF, 2018). Therefore, the performance of workers will soon be determined by how quickly and effectively they learn and adapt to the needs of their ever-changing jobs. 
One perspective to addressing this need is empowering workers to proactively redesign their jobs using a job crafting approach. This notion of job crafting has increasingly been seen as a major advance in work design theory due to its emphasis on bottom-up (employee-initiated) rather than the traditional top-down work design in which managers or employers create jobs and roles (Grant et al., 2010). The current study uses a quasi-experimental design to investigate the effect of a job crafting intervention on stimulating job crafting behaviors in participants. In addition, I test the extent to which this relationship is moderated by individuals' mindset.

\section{Job Crafting}

Today's organizations expect employees not only to adapt to implemented change, but also to introduce changes themselves (Grant \& Parker, 2009). The phenomenon of employees proactively shaping their jobs is known as job crafting and can be defined as how employees change the type and number of tasks and activities they do (task crafting), the way they interact with others at work (relational crafting), and how they cognitively frame the significance of their work (cognitive crafting) such as reframing responsibilities to create more meaningful work (Wrzesniewski \& Dutton, 2001). More recently, skill crafting has also been developed as an additional, important type of job crafting, and represents employees' self-initiated efforts to change their skills at work to better carry out their own jobs (Wrzesniewski et al., 2012).

For instance, a form of task crafting might represent efforts to seek out new projects and gains in one's job, such as adding complexity to tasks and increasing the 
scope of decisions made in the job. A form of relational crafting may involve meeting and interacting with a wider range of colleagues at work from whom one can learn from. In the same respect, those who engage in cognitive crafting will seek to gain new ways of viewing their overall job and will branch out, creating links between how their job contributes to a broader organizational and societal context. (Dall'Alba \& Sandberg, 2006). Finally, skill crafting might involve gaining a wide range of skills, for instance, by seeking out training opportunities and immersing oneself in stretch assignments (Bindl et al., 2019).

Overall, research supports these four distinct types of job crafting (Berg et al., 2010a; Berg et al., 2010b; Lyons, 2008) and suggests job crafting can promote important outcomes, such as changes to the meaning of work and one's work identity (Wrzesniewski \& Dutton, 2001), job satisfaction, work engagement, resilience and thrive (Berg et al., 2008).

Moreover, job crafting is also referred to as a self-initiated change behavior that employees engage in with the aim to align their jobs with their own individual needs such as their values, strengths, and passions (Bakker et al., 2012; Wrzesniewski \& Dutton, 2001). One study exemplifies this dynamic by examining the case of a maintenance technician who crafted his job in the form of taking on additional tasks. The worker reported that after being with his organization for some time, he proactively began helping newcomers to learn the job out of his personal passion of teaching others, which eventually resulted in a formal responsibility to train new employees (Berg et al., 2010b). 


\section{Job Crafting Intervention}

Contrasting with top-down interventions that are initiated by management (e.g., job analysis), a job crafting workshop provides a bottom-up intervention that helps individuals to understand how to deconstruct their job roles, identify their strengths and interests, and then find meaningful ways to improve their alignment between roles on one hand, and their strengths and interests on the other (Kooij et al., 2017). A critical difference between the two is that top-down approaches enhance the same job characteristics for all employees (even though not everybody attaches value to the same characteristics), while a bottom-up job crafting intervention would result in each employee changing different job characteristics depending on their own needs (Demerouti, 2014).

Accordingly, a job crafting workshop is expected to positively stimulate changes in job crafting behaviors in meaningful ways. First, by providing background principles on work design theories, participants become aware of the differences between top-down vs. bottom-up approaches (e.g., job design vs. job crafting), as well as the positive outcomes of the latter. Also, during the intervention participants have a clear overview of their job and are stimulated to view their roles as a flexible set of building blocks rather than a rigid list of tasks and duties (Berg et al., 2008).

Further, a successful intervention should also help participants to assess how their needs align with what they do day-to-day at work, and in response to this assessment, 
how they might diagnose better ways to achieve their motives, utilize and build on their strengths, and fulfill their passions (Berg et al., 2008).

Although there are several job design interventions that use a top-down approach, hardly any studies present the effectiveness of bottom-up interventions. One exception is a study of Japanese managers that aimed to test the effectiveness of a job crafting intervention on work engagement. The intervention program was designed based on the original conceptualization of job crafting by Wrzesniewski \& Dutton (2001), and consisted of two in-person training sessions, a job crafting exercise, and an individual job crafting plan. The study indicated that the intervention was effective in improving participants' level of job crafting both post-intervention and at one-month follow-up $(t=$ 2.36, $p=0.02$ : Cohen's $d=0.36$ at Time 2 and 0.47 at Time 3) (Sakuraya et al., 2016).

Therefore, the first aim of this study is to address this gap in research by investigating whether a job crafting intervention positively stimulates job crafting behaviors with a pretest-posttest study design. I hypothesize that the reported job crafting behavior for overall job crafting, as well as for specific job crafting strategies (task, relational, cognitive, and skill) will increase post-intervention (T3) both compared to the baseline (T1) and to the control group. Accordingly, the first hypothesis of the study is presented below.

Hypothesis 1: Participants' levels of (a) overall crafting, (b) task crafting, (c) relational crafting, (d) cognitive crafting, and (e) skill crafting will increase after the job 
crafting intervention (T3) both compared to their level prior to the intervention (T1) and compared to a control group.

To test this hypothesis, a job crafting intervention was developed to increase the awareness of participants regarding the ways in which they can shape their roles to adapt them to their own needs, as they may not naturally reflect on these topics without an intervention. The program consisted of three phases: (1) an online job crafting workshop; (2) a job crafting exercise; and (3) a job crafting action plan.

It was expected that the intervention would give participants the opportunity to improve their job crafting behaviors by learning theoretical background from the workshop, practicing how to craft their roles from the job crafting exercise, and setting an action plan followed by a 30-day period to implement such planned actions. Because content relevance, practice, and goal setting enhance transfer of training (Burke \& Hutchins, 2007), it was expected that participants of the job crafting intervention would conduct their own analysis of potential misfit between their personal values and beliefs and their roles and, therefore, work towards their own personal goals to improve said fit, which in turn will have a positive effect on job crafting behavior.

According to previous studies, job crafting interventions are usually performed based on the "Michigan Job Crafting ${ }^{\mathrm{TM}}$ Exercise (JCE)," an intervention developed to help both students and employees to redesign their roles (Berg et al., 2008). Consistently, the online training for this study was designed based on the "JCE Teaching Note," which was made accessible directly by the Job Crafting LLC, the exclusive distributor of the 
JCE. Finally, the training materials were developed based on the job crafting tool, also distributed by Job Crafting LLC. This step was taken to ensure the intervention for this study would follow the same approach used in similar previous studies.

\section{Job Crafting and Growth Mindset}

In addition to testing the job crafting intervention itself, I also propose that individual factors (i.e., mindset) moderate the extent to which the job crafting intervention influences a change in participants' individual job crafting behaviors. Mindsets are the implicit theories or assumptions that people hold about the plasticity of their abilities (Keating \& Heslin, 2015). People who hold an entity theory of intelligence (i.e., fixed mindset) view it as a fixed quantity that cannot be changed very much by effort and learning (Dweck, 1986). Employees that hold this mindset believe that intelligence is a matter of, "you have it or not," and there is not much you can do or learn to change it. In contrast, people who hold an incremental theory (i.e., growth mindset) believe intelligence is malleable and expandable (Dweck, 1986). Employees who attain this mindset believe that they can improve their intelligence and capabilities if they put enough effort into learning.

Moreover, drawing from this theory, it is expected that employees will react differently to job crafting depending on their mindset. For example, in line with the implicit theories of intelligence (Dweck, 1986), an employee's beliefs regarding their ability to learn will influence how they perceive skills as learnable, and not as abilities that only gifted people possess. Therefore, I propose that job crafting is a potential 
strategy that employees may use to deal with changes in their work, but the extent to which individuals will increase their levels of job crafting behavior is affected by their mindset. An additional aim of this thesis is, therefore, to introduce employee's mindset (growth vs. fixed) as a moderator of the effect of a job crafting intervention on reported job crafting behaviors (see Figure 1 for the proposed rationale). Accordingly, a second hypothesis of the study is presented below.

Hypothesis 2: Individuals' mindset moderates the effect of a job crafting intervention on job crafting behaviors, such that the effect when a growth mindset is present will be positive.

\section{Method}

\section{Participants}

The sample consisted of 275 undergraduate students enrolled in two mandatory psychology courses (Course A and Course B) at a large university in the western US. The courses were selected because the topics of goal setting and career development were relevant to the learning objectives of both courses, which enabled the intervention to be presented to the students as part of their course curriculum. Both Course A and Course B consisted of students who had completed at least half of their university credit requirements, but Course B students were approaching graduation during the next two semesters. At the end of the course, students were asked if their data could be used for research purposes and data were used only from those granting approval (50\% of the 552 enrolled students provided useable data for research purposes). Students in Course A ( $n=$ 
194 of 382 enrolled) were assigned to the control group whereas students in Course B ( $n$ $=81$ of 170 enrolled) were assigned to the experimental group. This procedure was followed to avoid contamination effects, where members of the experimental group may influence members of the control group or vice versa (Cook \& Campbell, 1979).

Demographics of the sample were as follows: $77 \%$ were female, the average age was 23 years $(S D=5.1)$, and the majority were Latino/a or Hispanic $(32 \%)$ and Caucasian (23\%). Additionally, 73\% were employed at the time of the study, and the average work life tenure was 50.67 months $(S D=34.3)$.

\section{Procedures}

The quasi-experimental design of this study consisted of pre- and postmeasurements. Participants from both groups completed three questionnaires in total through the students' online portal. Wave 1 consisted of measures of job crafting and mindset, which was administered 30 days before the workshop (T1). Wave 2 involved the online workshop and an evaluation survey to measure each participant's initial reactions to the workshop (T2). Wave 3 consisted of the post-measure of job crafting 30 days after the workshop (T3). The average time period between action plan submission (T2) and the post-intervention survey was 29 days $(S D=7.02)$. Last, both groups were addressed about the anonymity of their data and were assigned the same deadlines to complete each step of the experiment.

Control condition (Course A). Participants in the control group received a workshop on action planning followed by submitting a personal action plan (see 
Appendix D). The Action Plan Workshop consisted of a 6-minutes online session, which included several basic steps on how to create an action plan to change elements of one's job or student role.

Participants were prompted to start their action planning by first defining one to two actions to work on, then indicating up to three people who could help them accomplish these actions, while reflecting on potential challenges and barriers they might encounter when implementing their action plan as well as indicating strategies to overcome them. Finally, they were also prompted to think about the skills they would need to develop in order to successfully make changes to their jobs or student roles.

After watching the workshop, students were asked to submit their own personal action plan, in which they worked independently to implement the planned actions for 30 days. An example of an action plan for this group was: "Read journal articles about effective behavioral management techniques we can use in the daycare setting." Importantly, participants from this group did not receive any theoretical or practical background on job crafting at any point of the intervention.

Experimental condition (Course B). Participants in the experimental group completed the same action plan activity (see Appendix C) as the control group but were also presented additional lecture material about job crafting theory and completed a job crafting exercise (see Appendix B). The additional lecture material consisted of a 35minute online session, which began by providing background theory on job crafting and traditional views of job design (top-down vs. bottom-up approach), as well as presenting 
the positive outcomes of job crafting. Participants were also exposed to a study case that highlighted how job crafting strategies can materialize in real life.

The lecture also described the additional activity unique to the experimental group, the Job Crafting Exercise, in which participants were instructed to apply the crafting strategies following several steps. First, participants were asked to create a task block for each part of their job or student role. After identifying their tasks or projects, participants were asked to think about how much time and energy they typically spend on each block compared to other tasks. This step was called "Before Sketch."

In the next step, named "Mapping Yourself," participants were asked to consider their own individual needs by creating symbols to represent three important aspects of themselves at work or school: their values, strengths, and passions. They were instructed to select two to four elements of each aspect, all of which were provided with a short description. Example elements for values were "Autonomy" and "Growth," for strengths were "Judgement" and "Creativity," and for passions were "Leading" and "Thinking."

Subsequently, the participants were asked to build a more ideal, but still realistic version of their jobs or student life; a step called “After Diagram.” They began by crafting their tasks by adding, changing, removing or dropping tasks, whenever feasible. Then, they were asked to place their individual needs (e.g., values, strengths and passions) near the tasks they fit, and to examine better ways to perform their tasks to better suit their personal needs. Next, they also reviewed their relationships at work by discerning the individuals and groups that may benefit or be involved with their work in 
those tasks. Lastly, they were prompted to use role frames to craft how they envisioned the purpose of their work, as well as the role they would like to play in their jobs or school moving forward. At this point, it was reinforced how their individual needs could be better satisfied by working on specific tasks or projects, ultimately changing the meaning of their roles as employees or students.

In the final section of the workshop, and identically to the control group, participants were given a walkthrough on how to create their own personal action plan, in which they worked independently to implement the planned actions for 30 days. An example of an action plan for this group was: "Try to connect with employees more and ask them as well as management for feedback on my reports."

\section{Measures}

Job crafting. Job crafting was measured using an adapted version of the Job Crafting Questionnaire which has been reported to be reliable and valid (Bindl, Unsworth, Gibson, \& Stride, 2019). It contained 16 items assessing four subscales: task crafting (4 items; e.g., "I change my tasks so that they are more challenging"), relational crafting (4 items; e.g., "I actively seek to meet new people”), cognitive crafting (4 items; e.g., "I think about new ways of viewing my overall role"), and skill crafting (4 items; e.g., "I actively explore new skills"). To assess job crafting behaviors, respondents were asked about how often they had engaged in the different job crafting strategies over the past month at school or work. All items were measured on a five-point Likert scale ranging from 1 (never) to 5 (every day). For the post measure, participants were 
prompted to answer the questions by thinking about their experiences at work or school after they had created their action plan. Cronbach's alpha for pre/post-measures presented good or excellent reliability for all subscales, and are presented in Table 1.

Mindset. Mindset was measured using the Implicit Theories of Intelligence Scale (Dweck, 2000). It contained 8 items that included questions about how malleable or fixed respondents believe their intelligence is, which was administered before the intervention (T1). Participants had to score the items on a seven-point Likert scale, ranging from 1 (strongly disagree) to 7 (strongly agree). An example item is "No matter who you are, you can significantly change your intelligence level." Cronbach's alpha for the measure in the current study was .91 .

Manipulation check. A manipulation check was included to measure the differences between both interventions for the experimental group and the control group. It consisted of a single question about how the workshop and activities made the participants think about their personal values and beliefs. Participants had to score the item on a seven-point Likert scale, ranging from 1 (strongly disagree) to 7 (strongly agree). The item was "The lecture and activity made me think about my personal values and beliefs." As the control group didn't receive any stimulation to reflect on their personal strengths, values, and passions during the lecture or the activity, it was expected that they would react negatively to such statement. 


\section{Analysis}

To test the effect of the intervention (H1), a repeated measures ANOVA with a withinsubject factor representing time (T1-T3) was executed for the experimental group and the control group on the four job crafting subscales.

To test the moderation effect $(\mathrm{H} 2)$, a repeated measures GLM was executed with a within-subject factor representing time (T1-T3) and a between-subject factor representing levels of growth mindset (i.e., high vs low) controlling for each group condition (i.e., experimental vs control).

To test the manipulation check, an independent samples t-test was conducted to compare the manipulation check single-item in the control group and experimental group conditions. Finally, a one-way ANOVA was performed to test demographic and motivation differences between the two groups at the baseline level and post-intervention.

\section{Results}

The correlations between all study variables at both measurement points, means, standard deviations, and Cronbach's alpha coefficients are displayed in Table 1.

\section{Manipulation Check}

The manipulation check (independent samples t-test) revealed that participants in the experimental group $(M=5.49, S D=1.27)$ reported higher levels of thought about values $(t(273)=-2.28, p=.023)$, than participants in the control group $(M=5.10, S D=$ 1.30). This was expected because the control group didn't receive guidance during the workshop to reflect on their personal values and beliefs. Of note, both groups had mean 
scores that indicate participants engaged in some value reflection regardless of their intervention. This is likely because all participants were part of career development courses that encourage self-exploration.

\section{Main Effect of Job Crafting Intervention}

The central prediction of this study was that a job crafting intervention could influence changes on jo-b crafting behaviors. As such, I proposed that participants' levels of overall, task, relational, cognitive, and skill crafting, would increase over time for participants within the experimental condition compared to their level prior to the intervention. In addition, the increase in job crafting over time would be greater in the experimental condition compared to the control condition.

To test this hypothesis, a repeated measure analysis of variance (RM ANOVA) was executed for all job crafting variables for both condition groups.

Hypothesis 1 was not supported, which predicted an increase in job crafting for the experimental condition. The results showed no main effect of the job crafting intervention on $\mathrm{T} 3$ for the experimental group for any of the job crafting variables (see Table 2). Unexpectedly, participants from the control group (action plan activity only) reported significant increase in job crafting behavior for overall crafting $($ Mean $\mathrm{T} 1=3.24$, $S D=.86 ;$ Mean T3 $=3.35, S D=.84)(F(1,193)=3.8, p=.05, \eta p 2=.019)$, task crafting $($ Mean T1 $=2.65, S D=1.09 ;$ Mean T3 $=3.10, S D=1.01)(F(1,192)=42.2, p=.00, \eta p 2$ $=.180)$, and cognitive crafting (Mean $\mathrm{T} 1=3.26, S D=1.13 ;$ Mean $\mathrm{T} 3=3.42, S D=1.03$ ) $(F(1,193)=3.9, p=.05, \eta p 2=.020)$ compared to their level prior to the intervention. 


\section{Moderating Effect of Growth Mindset on Job Crafting Intervention}

An additional aim of this study was to test whether individuals' mindset would have a moderating effect in the relationship between a job crafting intervention and job crafting behaviors. To test this hypothesis, a repeated measures GLM analysis (withinsubjects) was conducted for all job crafting variables for both condition groups.

Hypothesis 2 was not supported, which predicted that participants who reported higher levels of a growth mindset would be more likely to increase their levels of job crafting after the intervention. Surprisingly, the results for the experimental group showed that there was a significant moderating effect of a growth mindset in the relationship between job crafting and job crafting behaviors for overall crafting $(F(1,81)$ $=6.85, p=.00, \eta p 2=.025)$, cognitive crafting $(F(1,81)=4.965, p=.02, \eta p 2=.018)$, and skill crafting $(F(1,81)=8.16, p=.00, \eta p 2=.029)$, however, in the opposite direction (see Figures 2-4). In other words, those high in growth mindset in the experimental group reported a decrease on their levels of job crafting after the job crafting intervention for the aforementioned variables, hence, contradicting the hypothesized effect. Finally, no significant moderating effect was found for task crafting $(F(1,81)=1.03, p=.30, \eta p 2=.004)$, and relational crafting $(F(1,81)=2.26, p=.13$, $\eta p 2=.008$ ) (see Figures 5-6). Oppositely, those lower in growth mindset in the experimental group reported an increase on their levels of crafting behaviors for all variables (see Figures 2-6). In addition, and as expected, no significant moderating effect was found for any of the variables for the control condition (see Figures 7-11). 


\section{Exploratory Analysis}

The opposite effect found for the moderation hypothesis has interestingly showed a pattern that only emerged for those high in growth mindset. On that account, additional analysis was conducted to clarify whether other measures of general personality, such as the Big Five (i.e., Openness, Conscientiousness, Extraversion, Agreeableness, and Neuroticism), would present a similar pattern given that growth mindset correlates to some of these traits such as Openness $(r=.20, p<.01)$, Conscientiousness $(r=.18, p<$ $.01)$, and Agreeableness $(r=.18, p<.01)$. However, no significant results were found for any of the job crafting variables tested for the Big Five as moderators.

\section{Discussion}

The present pretest-posttest study investigated the effect of a job crafting intervention on job crafting behaviors, and the extent to which this relationship is moderated by individuals' growth mindset. It was expected that after watching a job crafting workshop, practicing the job crafting exercise, and engaging in action planning, participants from the experimental group would have made changes to their tasks, relationships, skills, and the cognitive meaning of their jobs or student roles within a 30day period, and as a result, would have reported an increase in their levels of job crafting after that period. It was also expected that participants from this same group who reported higher levels of growth mindset would be more likely to report greater increases of their levels of job crafting behaviors after the intervention, compared to those who reported lower levels of growth mindset. Surprisingly, the study did not find support for 
both hypotheses indicating that a job crafting intervention may be an effective way to stimulate changes in job crafting behaviors, however, its use may be successful for some, but not others.

Regarding the intervention effectiveness (H1), participants from the experimental group didn't report a significant increase on their levels of job crafting behavior after the intervention (T3) for any of the variables in comparison to their baseline level (T1) and to the control group. Interestingly though, the moderation hypothesis (H2) did show that the intervention had a detrimental effect for some participants (i.e., high growth mindset), and a beneficial effect for others (i.e., low growth mindset). Taken together, these findings may indicate that the increase in results for those low in growth mindset were offset by the decrease in results for those high in growth mindset, and for that reason, the general findings of the intervention did not show a significant change as hypothesized.

Concerning the moderation hypothesis, the present effect was found in the opposite direction than predicted, namely, those high in growth mindset, who are in turn more likely to believe that intelligence is malleable and expandable, reported a significant decrease in their levels of overall crafting, cognitive crafting, and skill crafting after participating in the job crafting intervention. Interestingly, this pattern emerged only for those high in growth mindset and additional analysis that tested the Big Five as moderators, didn't present any similarity to this pattern. This evidence suggests that the effect found is a product of the unique features of growth mindset. That said, it's worth 
speculating that these results may reflect what has been recently called the "false growth mindset."

In this vein, Dweck (2016) explains that it is possible to move from having a fixed mindset to a growth mindset by changing one's personal beliefs. However, we should not block out our fixed mindset thoughts and deeds but instead embrace them and try to work with and through them. The danger of blocking these thoughts is that we can end up with a false growth mindset (Dweck, 2016). A false growth mindset can be explained as someone who claims they have a growth mindset, but their actions don't follow through. Having a growth mindset does not only involve being open and believing one can change and therefore evolve, but also encompasses effort and strategy (Dweck, 2016). In other words, embracing a growth mindset is not only about learning, but transforming learning into action, which in turn is brought about through effort, by trying new strategies, and by seeking appropriate help and input. In that sense, a job crafting intervention involves more than learning about the strategies or believing that one can make changes to their jobs or student roles. Job crafting demands goal setting and relies on participants promoting said changes on their own for a certain period. Perhaps, the decline in the levels of job crafting found in this study for those who claimed to be bearing high levels of growth mindset had, in fact, reflected the phenomenon of a false growth mindset in the sense that this decline may be their own realization that they have not put their actions into place and, therefore, have not perceived any changes in their job crafting behaviors. Unfortunately, the data collected in this study does not allow us to test this assumption 
since we did not collect a second measure of mindset post intervention (T3). Such measure would enable us to further explore whether those who reported having a growth mindset at first would have changed their perceptions of their own mindsets after the intervention.

Also, an interesting finding from the moderation analysis was the effect that the intervention had on those low in growth mindset, such that those with a fixed mindset showed an increase in their levels of job crafting for all variables after the intervention. This finding indicates that a job crafting intervention may be beneficial for employees or students who lack personal resources by bearing a low growth mindset. A fixed mindset (i.e., low growth mindset) is associated with a focus on performance goals, lack of task enjoyment, being defensive, avoiding challenges, being competitive, giving up when tasks get hard, losing motivation after setbacks, and being less prepared to invest in one's own development and in the development of other people (Dweck, 2006). All these characteristics may reflect a lack of personal resources from these individuals who hold the belief that their intelligence and capabilities are static and can't change much. A job crafting intervention stimulates participants to reflect on their personal needs such as their values, passions, and strengths with the aim to reshape their roles as employees or students. By doing so, participants conduct their own analysis of potential misfit between their personal values and beliefs and their roles and, therefore, work towards their own personal goals to improve said fit and make changes to their roles. In such way, the job crafting intervention may have helped these individuals by providing them skills and 
structure to compensate for their lack of personal resources, as maybe, those are insights they wouldn't have on their own because they lack the belief that their capabilities are changeable.

\section{Strengths}

The present study makes three main theoretical contributions. First, as far as I know, this is an original study that has investigated individuals' mindset as a potential moderator of the relationship between a job crafting intervention and job crafting behaviors.

Furthermore, though unexpected, the study showed a unique pattern of how participants with high levels of growth mindset reacted to the proposed intervention, which may reflect a side effect of growth mindset that has not been explored in an experimental study before. Conversely, the study also presented a beneficial effect of the intervention for people who bear a low growth mindset, as the intervention may help them to compensate their lack of personal resources.

In a practical sense, these contributions are important to inform organizational psychologists whom intend to promote job crafting as a bottom-up approach in their organizations on how individuals' mindset can play a role on the way they react to a job crafting intervention, and thus, adapt the program accordingly by perhaps adding new sections to the workshop that would address such differences in mindset, or assisting participants individually with different resources based on their type of mindset. 
Finally, the training materials developed for this intervention may be of good use for educational purposes, such as for career coaching/development, as participants in the experimental condition reported positive attitudes on their initial reactions to the workshop, indicating that the lecture and activity content were relevant to their job/student role $(M=5.37 ; S D=1.44)$, and were motivating $(M=5.62 ; S D=1.07)$ and self-assuring $(M=5.70 ; S D=1.02)$.

\section{Limitations}

This study has some limitations that should be mentioned. First, participants in this study were not randomly assigned to condition groups. In this respect, it's worth mentioning that both demographic and motivation differences between the two groups may have influenced the results related to the intervention effectiveness $(\mathrm{H} 1)$. In terms of age, participants in the control group $(M=22.62 ; S D=4.50)$ were slightly younger than participants in the experimental group $(M=24.18 ; S D=6.17)(F(1,262)=5.262, p=$ $.02, \eta p 2=.020)$, and reported less work tenure $(M=46.61 ; S D=33.33)(F(1,265)=$ $9.377, p=.00, \eta p 2=.034)$ compared to the experimental group $(M=60.61 ; S D=34.93)$. In terms of motivation levels, participants in the control condition reported higher levels of motivation to achieve the goals listed in their action plans $(F(1,275)=8.147 ; p=.00$; $n p 2=.029)$, as well as, higher levels of confidence in their ability to execute the actions they planned $(F(1,273)=8.901 ; p=.00 ; n p 2=.032)$. Lastly, they also reported higher levels of action plan success after the 30-day period in comparison to the experimental group $(F(1,275)=8.407 ; p=.00 ; n p 2=.030)$. Perhaps, both demographics and 
motivation characteristics of the control group may have maximized response inflation in their post intervention self-reports, which in turn, may explain why said group that received the workshop on action planning only, showed significant increases in their levels of job crafting for some of the variables from baseline level (T1) to postintervention (T3).

In addition, the online modality alone may not have been enough for participants to fully absorb the activity and to work towards their action plan. Interaction between participants in in-person training sessions is known to stimulate learning and hold participants accountable for implementing their action plans. Having people make a public commitment to a goal enhances their commitment to it, presumably because acting contrary to their public pronouncement would induce the personally and socially undesirable impression of hypocrisy (Cialdini, 2001; Heslin et al., 2009). Future studies that adopt an online modality should give participants the opportunity to discuss and share their reflections during the workshop, as well as to interact with the instructor after the intervention. An additional recommendation is to insert a one-time follow-up between the action planning submission (T2) and the end of the 30-day period (T3), when instructors and participants can evaluate whether participants are succeeding in accomplishing their job crafting goals together during a one-on-one session.

In the same note, another limitation of this study is the short time frame for implementing the job crafting action plan, which may not be enough for participants to promote long lasting improvements. Job crafting strategies, such as task and cognitive 
crafting, might be accomplished in a short-term period; however, relational and skill crafting may require more time to not only implement the planned changes but also to perceive that such changes took place. Therefore, future studies should consider increasing the amount of time for participants to implement their action plan to up to 90 days, as well as to insert a 6-month follow-up after the intervention to test for long-term changes.

Lastly, this study used only self-report measures, which can result in common method biases (Podsakoff et al., 2012). Future studies should add objective indicators of crafting behaviors, such as observations by supervisors or colleagues. Similarly, it is also reasonable to assume that having such leadership and team support might increase the likelihood of participants committing to their actions and thus increasing their job crafting behaviors.

\section{Future Directions}

Although with limited evidence, this study may have uncovered a possible side effect of bearing a growth mindset when engaging in job crafting. To my knowledge and up to this point, no scientific research has been conducted to further understand said phenomenon, except for a theoretical contribution made by the original author of the implicit theories of intelligence which was drawn from her own observations of more than 30 years of research on the topic (Dweck, 2016). Therefore, future research would benefit from exploring whether growth mindset may promote such a side effect when individuals are faced with goal setting and action taking, specifically. Such study could 
explore whether an individual's level of growth mindset would change after being exposed to activities in which they should engage in some sort of action planning. A decrease in their levels of growth mindset, in comparison to their baseline level, could indicate that a false growth mindset may be revealed after individuals are confronted with the need to take an action that aligns to their beliefs of being capable of evolving and expanding their capabilities and intelligence.

Additionally, to further explore how the intervention may provide skills to compensate for individuals' low growth mindset, future research would benefit from testing whether a job crafting approach would be more effective when combined with other types of interventions. More specifically, what are the mechanisms from which job crafting, when combined with other resources, may further stimulate job crafting behaviors. In the same vein, Wrzesniewski and colleagues (2012) have suggested that job crafting may be necessary but insufficient for lasting improvements. After conducting a field quasi-experimental study in a Fortune 500 technology company, in which they compared the effects of engaging in job crafting versus engaging in job crafting in concert with skills development on employee happiness, they found that the latter takes longer to realize but has greater and longer-lasting effects (at least 6 months) than job crafting does alone (Wrzesniewski et al., 2012). Feasibly, another alternative may be to combine a job crafting intervention with a personal resources intervention in which participants learn to increase their personal resources, and in turn, experience an increase 
in their confidence and capability of crafting their jobs (Wingerden et al., 2015). These findings could indicate what type of personal resources (e.g., hope, optimist, selfefficacy, and resilience) could better enhance job resources (e.g., task, relational, cognitive or skill crafting), as well as what type of skills could be better developed through job crafting (e.g., technical skills versus soft skills), and therefore shape the different approaches organizations could take to help their employees' development based on their individual needs.

In conclusion, this paper contributes to the job crafting literature in the extent to which it uncovers whether job crafting represents a successful strategy that will help individuals to learn and adapt to their ever-changing jobs. A disruptive future may arrive before humans discover whether they have the ability to cope with it. As scientists, we may be capable of building conceptual models of future scenarios; however, we often neglect to spend time predicting how we need to evolve to make such future scenarios a normal part of our present. We should dwell on how we can evolve our actions and interactions to keep pace with the changes in the technology around us. I-O psychologists can play a key role in helping leaders and employees with this transformation, by designing learning and development programs that focus on interventions that promote this change in mindset. This study aimed to present job crafting as one alternative to support the evolution of work, in which employees not only react and adapt to unavoidable - and sometimes profound - changes of their jobs, but also create and implement them. 


\section{REFERENCES}

Bakker, A. B., Tims, M., \& Derks, D. (2012). Proactive personality and job performance: The role of job crafting and work engagement. Department of Work \& Organizational Psychology, 65(10), 1359-1378.

Berg, J. M., Dutton, J. E., \& Wrzesniewski , A. (2008). What is Job Crafting and Why Does It Matter? University of Michigan Ross School of Business.

Berg, J. M., Grant, A. M., \& Johnson, V. (2010). When Callings Are Calling: Crafting Work and Leisure in Pursuit of Unanswered Occupational Callings. Organization Science, 21(5), 973-994.

Berg, J. M., Wrzesniewski, A., \& Dutton, J. E. (2010). Perceiving and responding to challenges in job crafting at different ranks: When proactivity requires adaptivity. Journal of Organizational Behavior, 31, 158-186. doi:10.1002/job.645

Bindl, U. K., Unsworth, K. L., Gibson, C. B., \& Stride, C. B. (2019). Job Crafting Revisited: Implications of an Extended Framework for Active Changes at Work. Journal of Applied Psychology, 104(5), 605-628.

Bughin, J., Hazan, E., Lund, S., Dahlström, P., Wiesinger, A., \& Subramaniam, A. (2018). Skill shift: Automation and the future of the workforce. McKinsey Global Institute. Retrieved from https://www.mckinsey.com/ /media/McKinsey/Featured\%20Insights/Future\%20o f\%20Organizations/Skill\%20shift \%20Automation\%20and\%20the \%20future $\% 20$ of $\% 20$ the $\% 20$ workforce/MGI-Skill-Shift-Automation-and-future-of-theworkforce-May-2018.ashx

Burke, L. A., \& Hutchins, H. M. (2007). Training Transfer: An Integrative Literature Review. Human Resource Development Review, 6(3), 263-296. doi:10.1177/1534484307303035

Cialdini, R. B. (2001). Influence: Science and practice. Needham Heights, MA: Allyn \& Bacon.

Cook, T. D., \& Campbell, D. T. (1979). Quasi-experimentation: Design and analysis issues for field settings. Boston, MA: Houghton Mifflin. 
Dall'Alba, G., \& Sandberg, J. (2006). Unveiling Professional Development: A Critical Review of Stage Models. Review of Educational Research, 383-412.

Demerouti, E. (2014). Design Your Own Job Through Job Crafting. European Psychologist, 19(4), 237-247.

Dweck, C. S. (1986). Motivational processes affecting learning. American Psychologist, 4l(10), 1040-1048. doi:10.1037/0003-066X.41.10.1040

Dweck, C. S. (2000). Self-theories: Their role in motivation, personality and development. Philadelphia, PA: Taylor \& Francis.

Dweck, C. S. (2006). Mindset: The New Psychology of Success. New York: Random House.

Dweck, C. S. (2016). Mindset: the new psychology of success. New York: Ballantines Book.

Grace, K., Salvatier, J., Dafoe, A., Zhang, B., \& Evans, O. (2018). When Will AI Exceed Human Performance? Evidence from AI Experts. ArXiv.org.

Grant, A. M., \& Parker, S. K. (2009). 7 Redesigning Work Design Theories: The Rise of Relational and Proactive. The Academy of Management Annals, 3(1), 317-375. doi:10.1080/19416520903047327

Grant, A. M., Fried, Y., Parker, S. K., \& Frese, M. (2010). n Putting job design in context: Introduction to the special issue. Journal of Organizational Behavior(31), 145-157.

Heslin, P. A., Carson, J. B., \& Vandewalle, D. (2009). Practical Applications of Goal Setting Theory to Performance Management. In J. W. Smither, Performance Management: Putting Research into Action (pp. 89-116). San Francisco, CA: Jossey-Bass.

Keating, L. A., \& Heslin, P. A. (2015). The potential role of mindsets in unleashing employee engagement. Human Resource Management Review, 329-341. doi:10.1016/j.hrmr.2015.01.008 
Kooij, D. T., van Woerkom, M., Wilkenloh, J., Dorenbosch, L., \& Denissen, J. J. (2017). Job Crafting Towards Strengths and Interests: The Effects of a Job Crafting Intervention on Person-Job Fit and the Role of Age. Journal of Applied Psychology, 102(6), 971-981.

Lyons, P. (2008). The Crafting of Jobs and Individual Differences. Journal of Business and Psychology, 23(1-2), 25-36. doi:10.1007/s10869-008-9080-2

Podsakoff, P. M., MacKenzie, S. B., \& Podsakoff, N. P. (2012). Sources of Method Bias in Social Science Research and Recommendations on How to Control It. Annual Review of Psychology, 63, 539-569. doi:doi.org/10.1146/annurev-psych-120710100452

Sakuraya, A., Shimazu, A., Imamura, K., Namba, K., \& Kawakami, N. (2016). Effects of a job crafting intervention program on work engagement among Japanese employees: a pretest-posttest study. BMC Psychol, 4(1).

Wingerden, J. V., Derks, D., \& Bakker, A. B. (2015). The impact of Personal Resources and Job Crafting Interventions on Work Engagement and Perfomance. Human Resource Management, 51-67.

World Economic Forum. (2018). The Future of Jobs Report. Geneva: World Economic Forum. Retrieved from http://www3.weforum.org/docs/WEF_Future_of_Jobs_2018.pdf

Wrzesniewski, A., \& Dutton, J. E. (2001). Crafting a Job: Revisioning Employees as Active Crafters of Their Work. The Academy of Management Review, 26(2), 179201. Retrieved from http://www.jstor.org/stable/259118

Wrzesniewski, A., Berg, J. M., Grant, A. M., Kurkoski, J., \& Welle, B. (2012). Job crafting in motion: Achieving sustainable gains in happiness and performance. Annual Meeting of the Academy of Management. Boston, MA. 
Table 1

Descriptive Statistics and Correlations for Study Variables

\begin{tabular}{|c|c|c|c|c|c|c|c|c|c|c|c|c|c|}
\hline Variable & $M$ & $S D$ & 1 & 2 & 3 & 4 & 5 & 6 & 7 & 8 & 9 & 10 & 11 \\
\hline 1. Overall Crafting T1 & 3.21 & .87 & $(.82)$ & & & & & & & & & & \\
\hline 2. Overall Crafting T3 & 3.29 & .85 & $.55^{* *}$ & $(.85)$ & & & & & & & & & \\
\hline 3. Task Crafting T1 & 2.65 & 1.08 & $.82 * *$ & $.49^{* *}$ & $(.89)$ & & & & & & & & \\
\hline 4. Task Crafting T3 & 3.02 & 1.04 & $.50 * *$ & $.84^{* *}$ & $.53^{* *}$ & $(.89)$ & & & & & & & \\
\hline 5. Relational Crafting T1 & 3.39 & 1.06 & $.73^{* *}$ & $.40^{* *}$ & $.43^{* *}$ & $.31 * *$ & $(.86)$ & & & & & & \\
\hline 6. Relational Crafting T3 & 3.27 & 1.04 & $.38 * *$ & $.79 * *$ & $.28^{* *}$ & $.51^{* *}$ & $.42 * *$ & $(.90)$ & & & & & \\
\hline 7. Cognitive Crafting T1 & 3.23 & 1.13 & $.81^{* *}$ & $.41^{* *}$ & $.57^{* *}$ & $.37^{* *}$ & $.43^{* *}$ & $.24 * *$ & $(.85)$ & & & & \\
\hline 8. Cognitive Crafting T3 & 3.39 & 1.04 & $.49 * *$ & $.83^{* *}$ & $.43^{* *}$ & $.62 * *$ & $.31^{* *}$ & $.52 * *$ & $.42 * *$ & $(.86)$ & & & \\
\hline 9. Skill Crafting T1 & 3.57 & 1.05 & $.84 * *$ & $.48^{* *}$ & $.62 * *$ & $.40^{* *}$ & $.51^{* *}$ & $.29 * *$ & $.59^{* *}$ & $.41^{* *}$ & $(.91)$ & & \\
\hline 10. Skill Crafting T3 & 3.49 & .98 & $.47 * *$ & $.87^{* *}$ & $.39^{* *}$ & $.66^{* *}$ & $.30^{* *}$ & $.62 * *$ & $.33^{* *}$ & $.64 * *$ & $.49 * *$ & $(.91)$ & \\
\hline 11. Growth Mindset $\mathrm{T} 1$ & 5.19 & .88 & $.16^{* *}$ & .05 & .11 & .11 & .08 & -.01 & $.16^{* *}$ & .00 & $.19^{* *}$ & .05 & $(.91)$ \\
\hline
\end{tabular}

Notes: This table displays Cronbach's Alpha Coefficients on the Diagonal for all study variables.

$\mathrm{M}=$ mean; $\mathrm{SD}=$ standard deviation; $\mathrm{n}=268$

*correlation is significant at the 0.05 level (2-tailed)

** correlation is significant at the 0.01 level (2-tailed) 
Table 2

Mean scores and repeated measures ANOVAs for job crafting variables within subjects by groups

\begin{tabular}{|c|c|c|c|c|c|c|}
\hline Variable & & & $\begin{array}{l}\text { Experimental Group } \\
\qquad(N=81)\end{array}$ & & & $\begin{array}{c}\text { Control Group } \\
\qquad(N=194)\end{array}$ \\
\hline Variables & T1 & T3 & RM ANOVA & T1 & T3 & RM ANOVA \\
\hline 1. Overall Crafting & 3.13 & 3.15 & $\mathrm{~F}(1,80)=.04 ; p=.84 ; \eta \mathrm{p}^{2}=.001$ & 3.24 & $3.35^{*}$ & $\mathrm{~F}(1,193)=3.82 ; p=.05 ; \eta p^{2}=.019$ \\
\hline 2. Task Crafting & 2.66 & 2.83 & $\mathrm{~F}(1,79)=1.72 ; p=.19 ; \eta p^{2}=.021$ & 2.65 & $3.10 *$ & $\mathrm{~F}(1,192)=42.26 ; p=.00 ; \eta p^{2}=.180$ \\
\hline 3. Relational Crafting & 3.23 & 3.11 & $\mathrm{~F}(1,80)=1.03 ; p=.31 ; \eta p^{2}=.013$ & 3.46 & 3.33 & $\mathrm{~F}(1,193)=2.53 ; p=.11 ; \eta p^{2}=.013$ \\
\hline 4. Cognitive Crafting & 3.17 & 3.33 & $\mathrm{~F}(1,80)=1.35 ; p=.24 ; \eta p^{2}=.017$ & 3.26 & $3.42 *$ & $\mathrm{~F}(1,193)=3.92 ; p=.05 ; \eta p^{2}=.020$ \\
\hline 5. Skill Crafting & 3.49 & 3.33 & $\mathrm{~F}(1,79)=1.06 ; p=.30 ; \eta p^{2}=.013$ & 3.60 & 3.56 & $\mathrm{~F}(1,192)=.38 ; p=.53 ; \eta p^{2}=.002$ \\
\hline
\end{tabular}

Notes: $\mathrm{N}=$ total participants

$* p<.05$ 
Figure 1

Hypotheses Testing Model

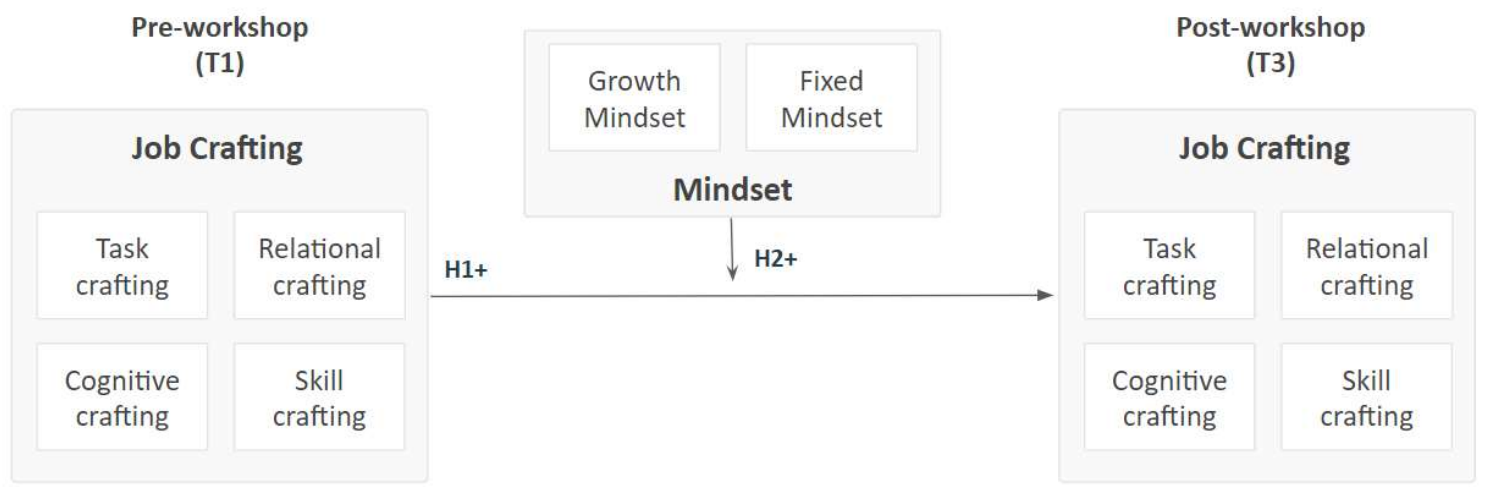


Figure 2

Moderation effect of a Growth Mindset on Overall Crafting for Course B

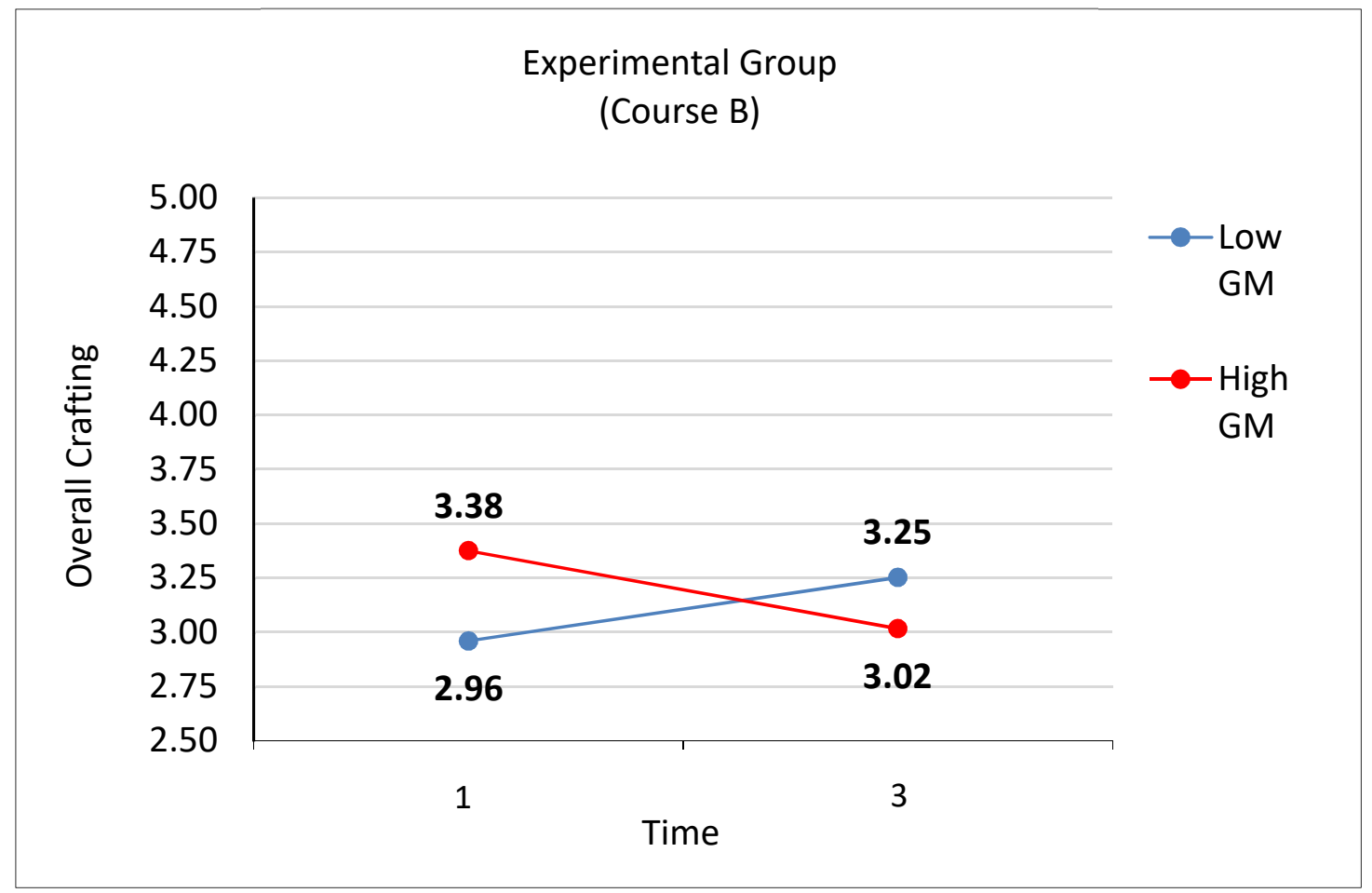

Notes: GM = Growth Mindset 
Figure 3

Moderation effect of a Growth Mindset on Cognitive Crafting for Course B

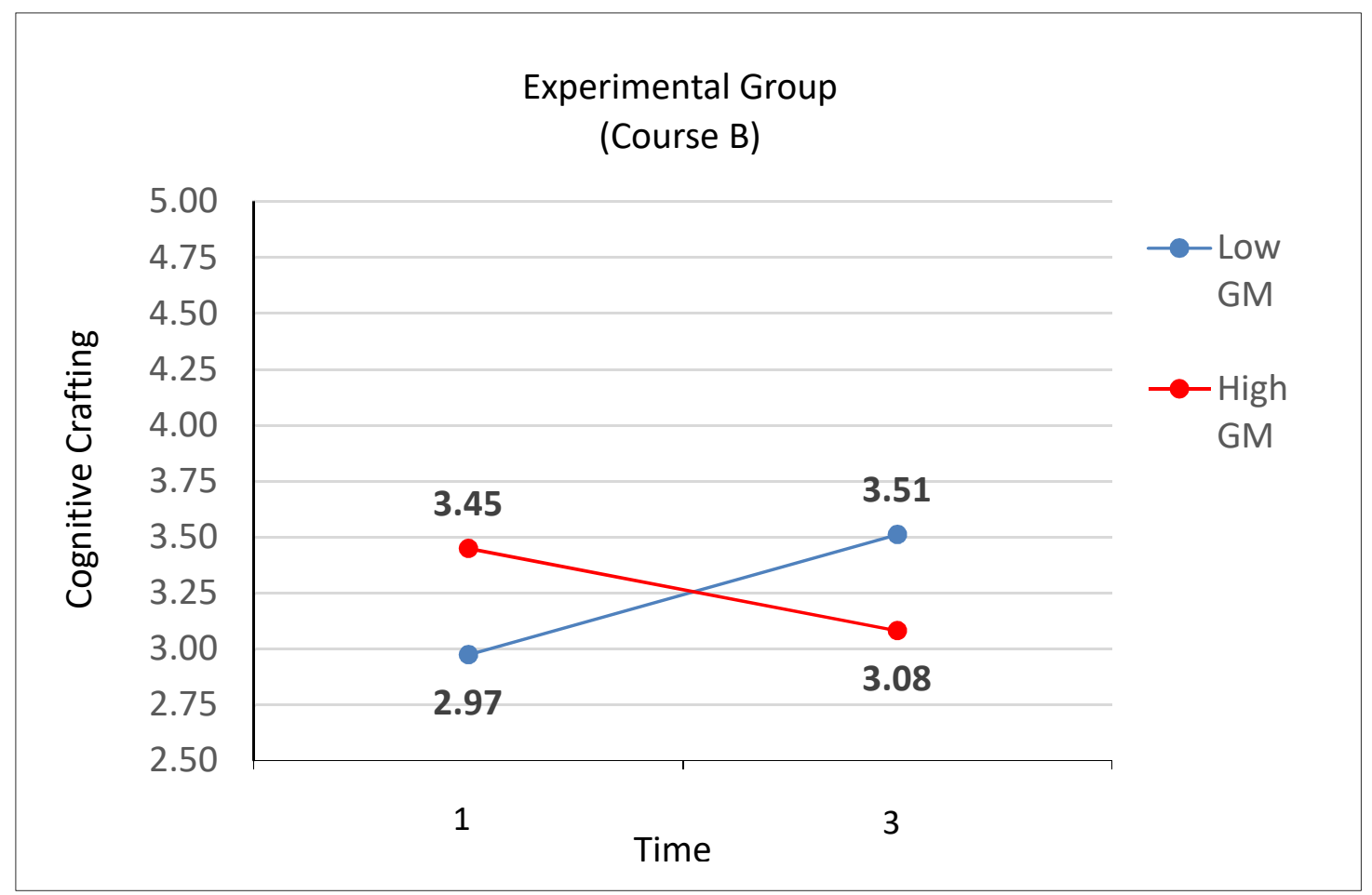

Notes: $\mathrm{GM}=$ Growth Mindset 
Figure 4

Moderation effect of a Growth Mindset on Skill Crafting for Course B

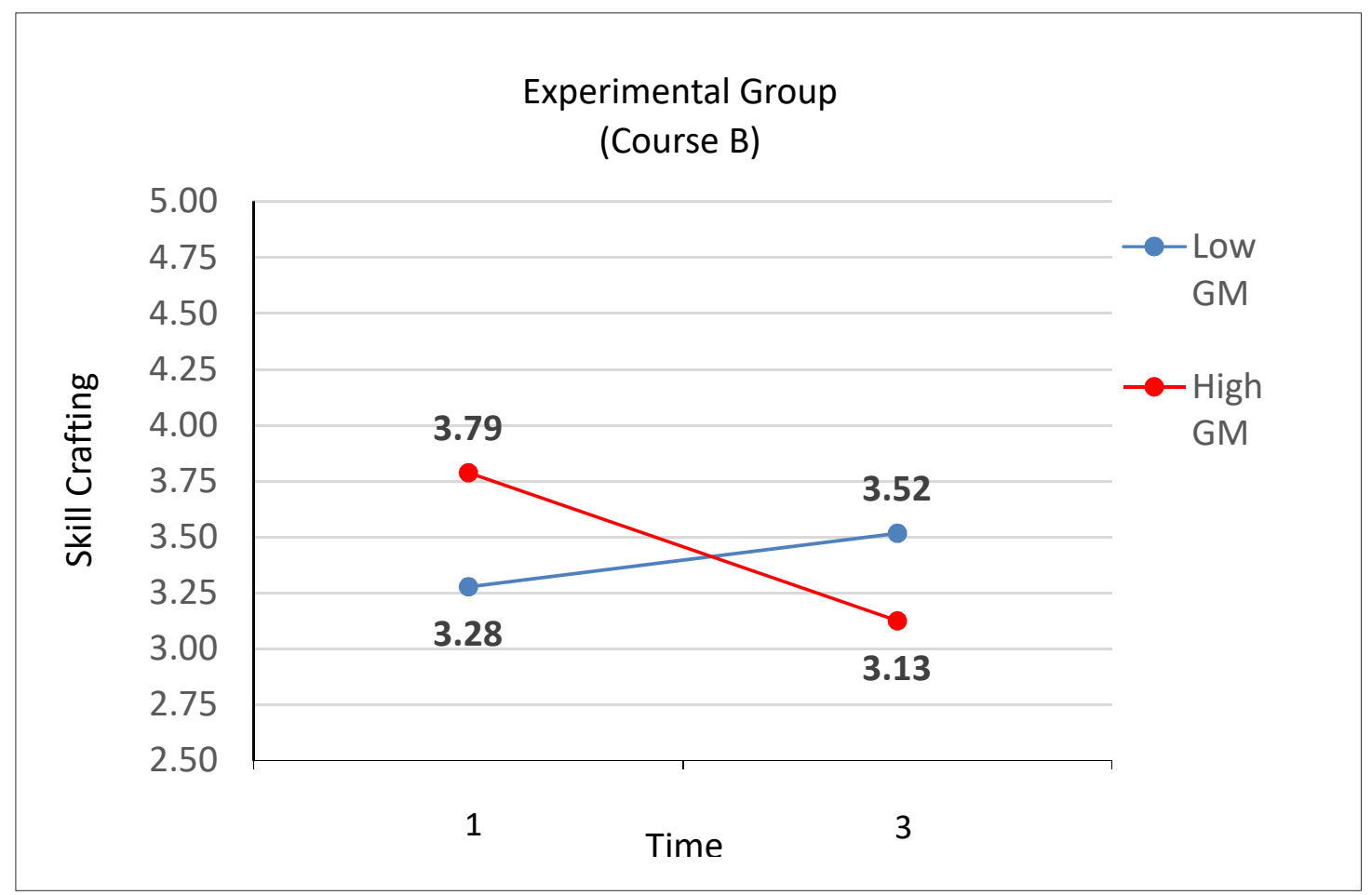

Notes: $\mathrm{GM}=$ Growth Mindset 
Figure 5

Moderation effect of a Growth Mindset on Task Crafting for Course B

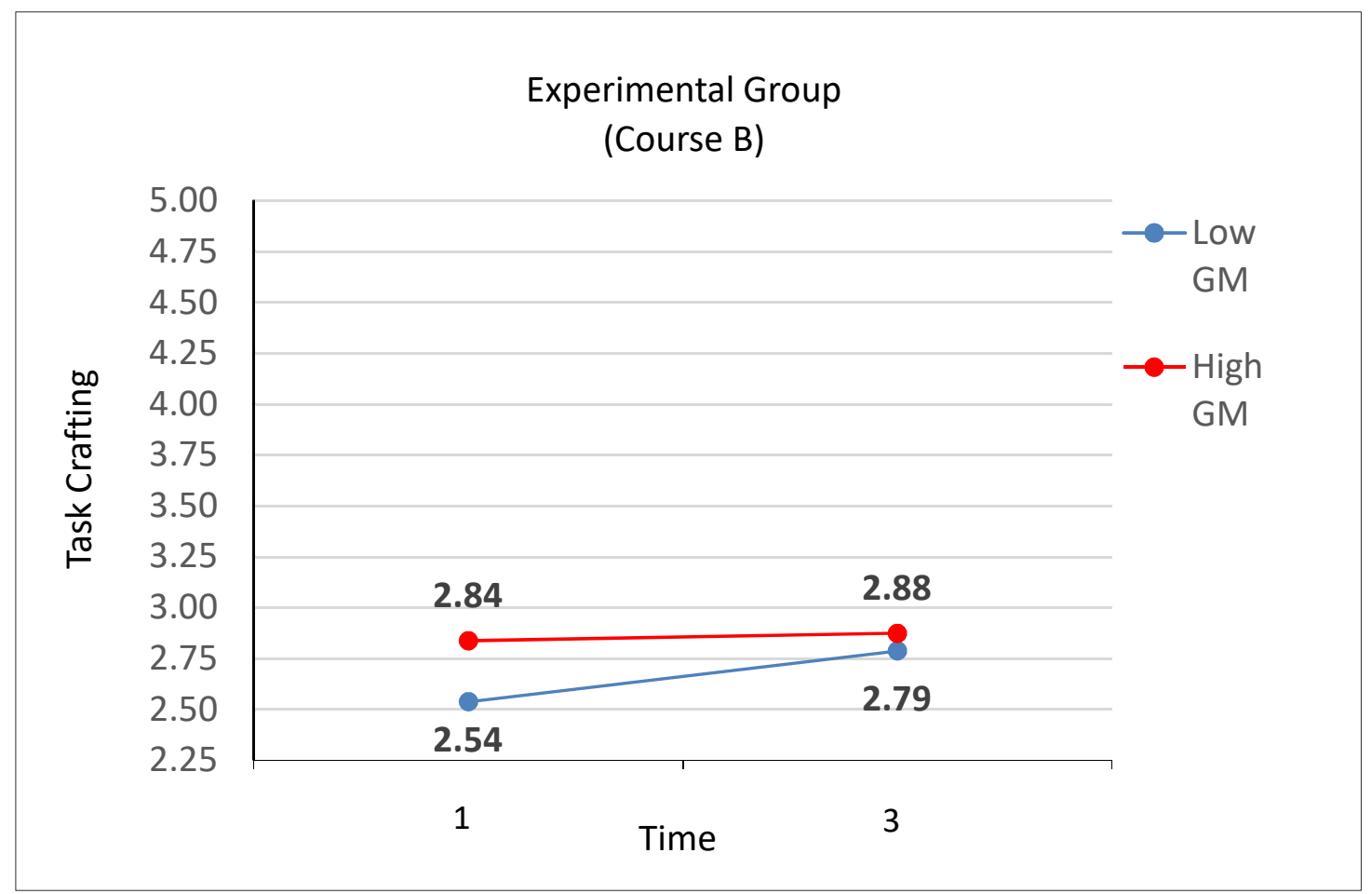

Notes: $\mathrm{GM}=$ Growth Mindset 
Figure 6

Moderation effect of a Growth Mindset on Relational Crafting for Course B

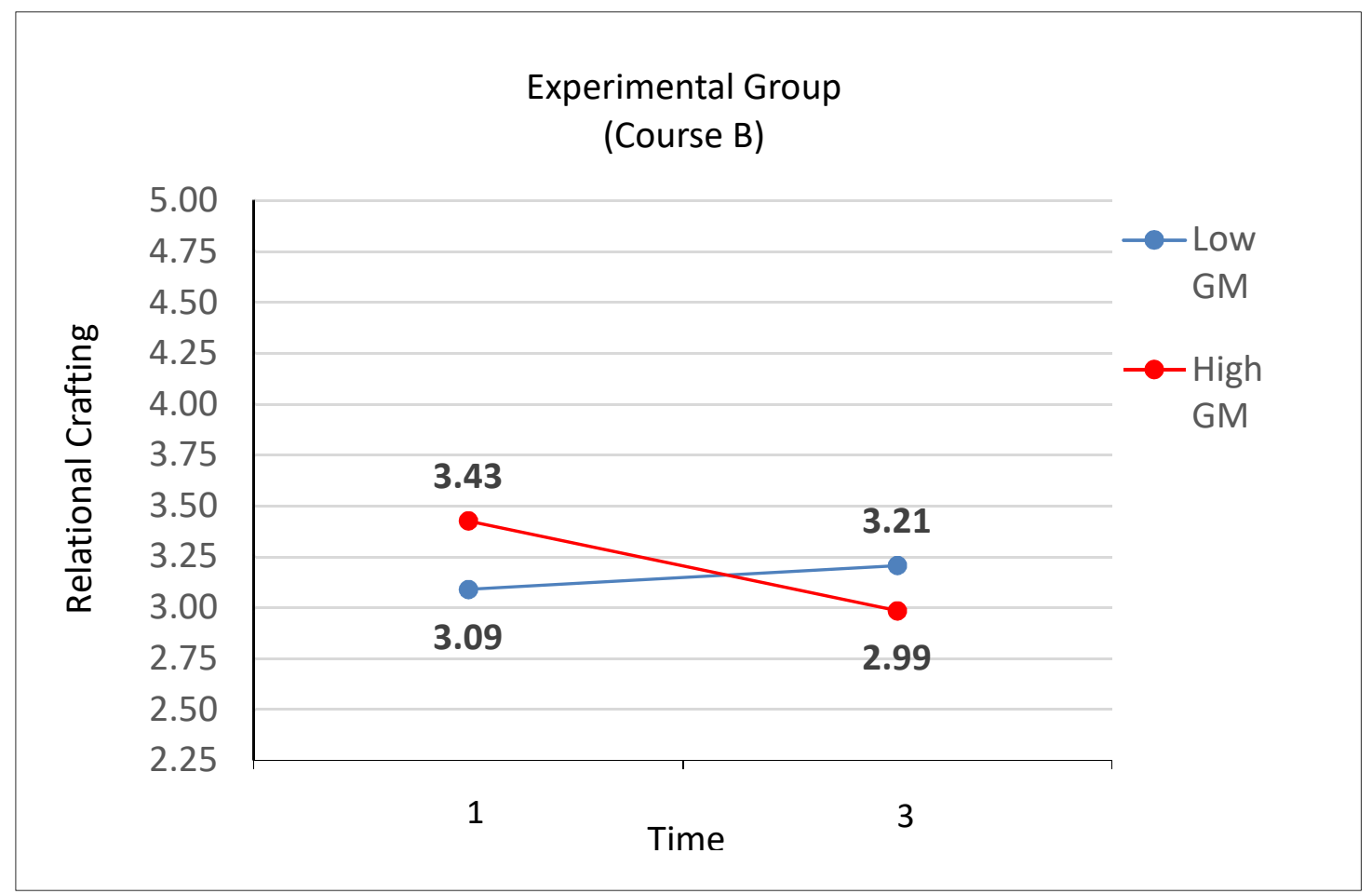

Notes: $\mathrm{GM}=$ Growth Mindset 
Figure 7

Moderation effect of a Growth Mindset on Overall Crafting for Course A

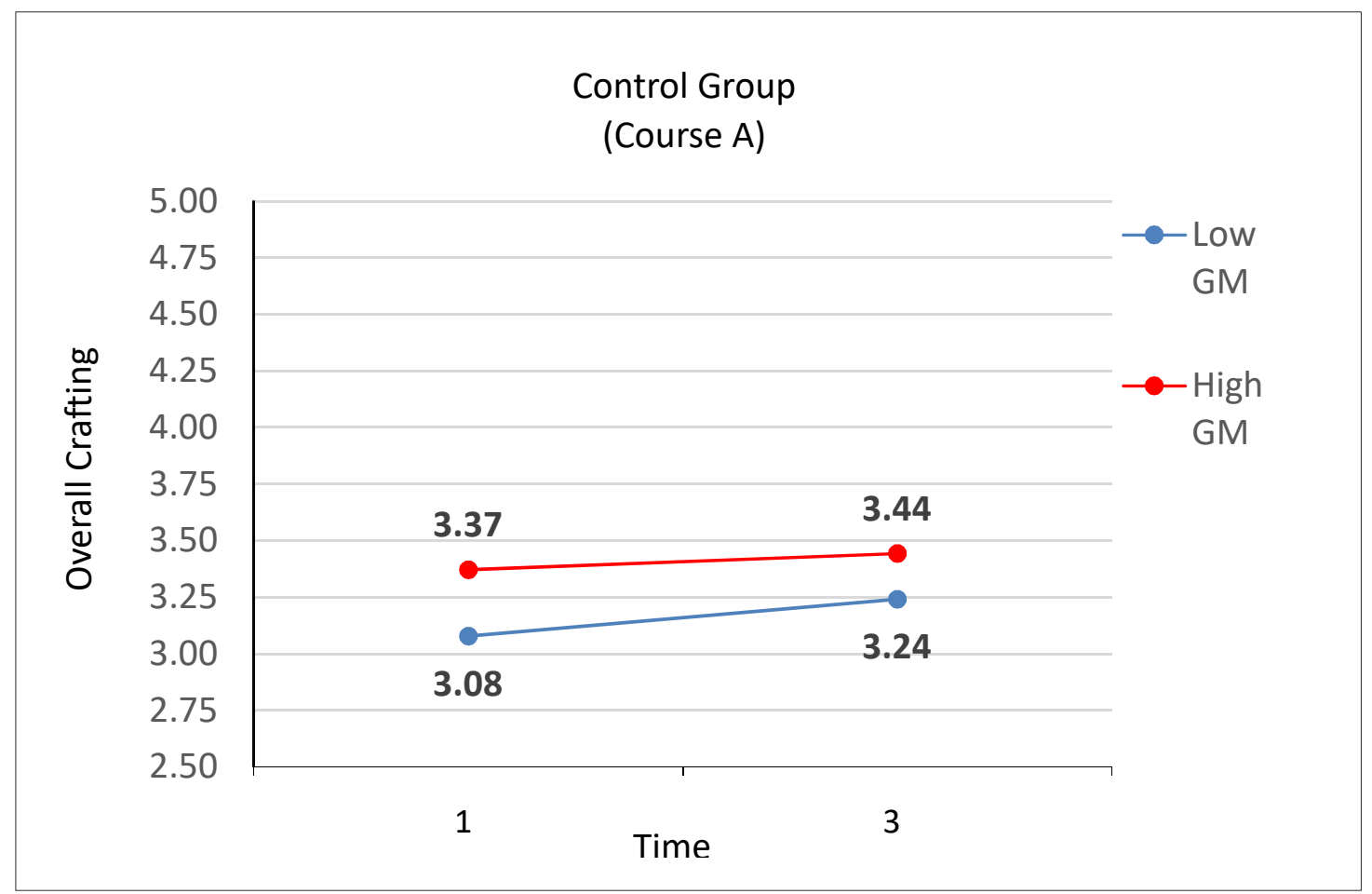

Notes: GM $=$ Growth Mindset 
Figure 8

Moderation effect of a Growth Mindset on Cognitive Crafting for Course A

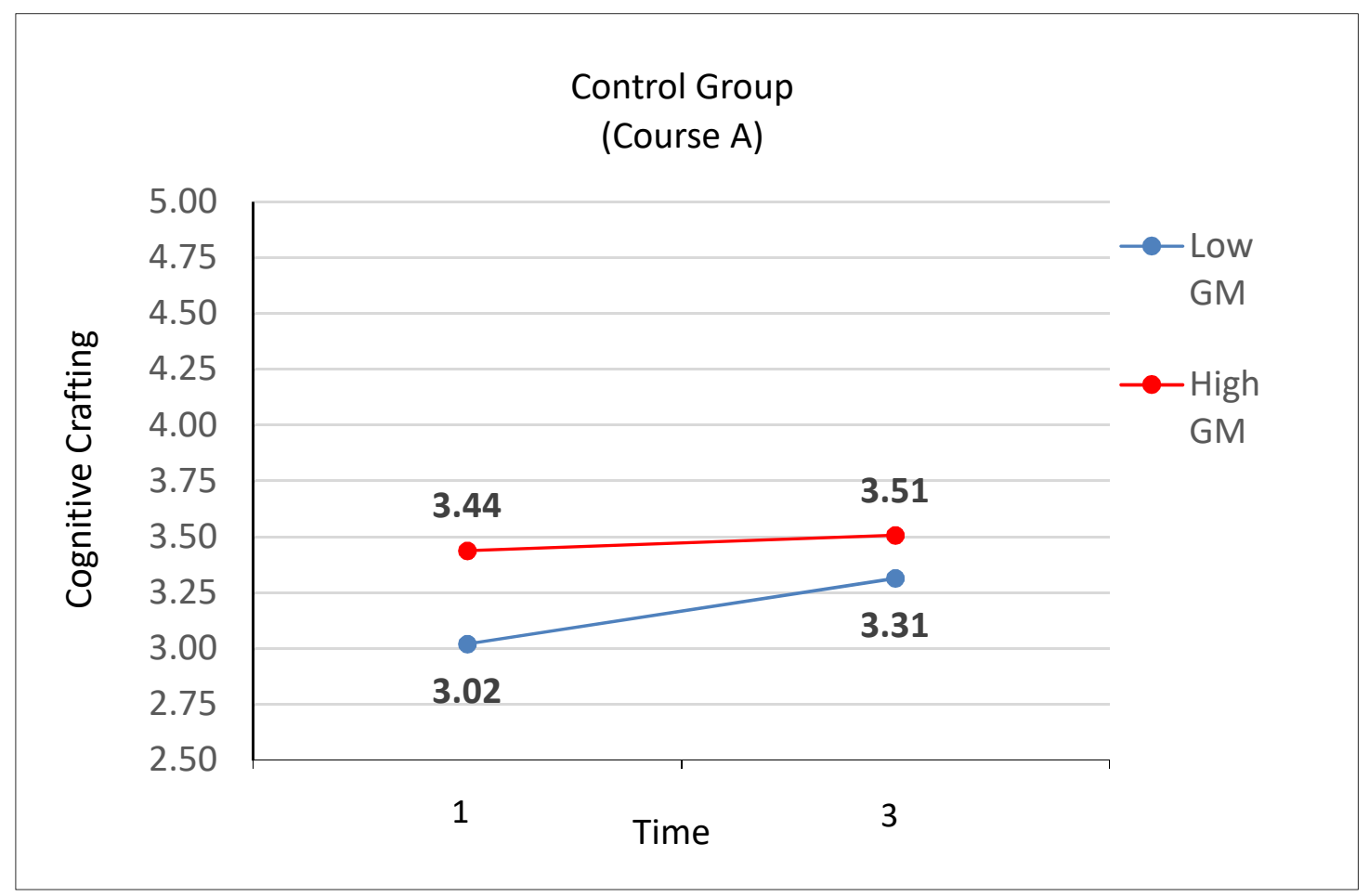

Notes: $\mathrm{GM}=$ Growth Mindset 
Figure 9

Moderation effect of a Growth Mindset on Skill Crafting for Course A

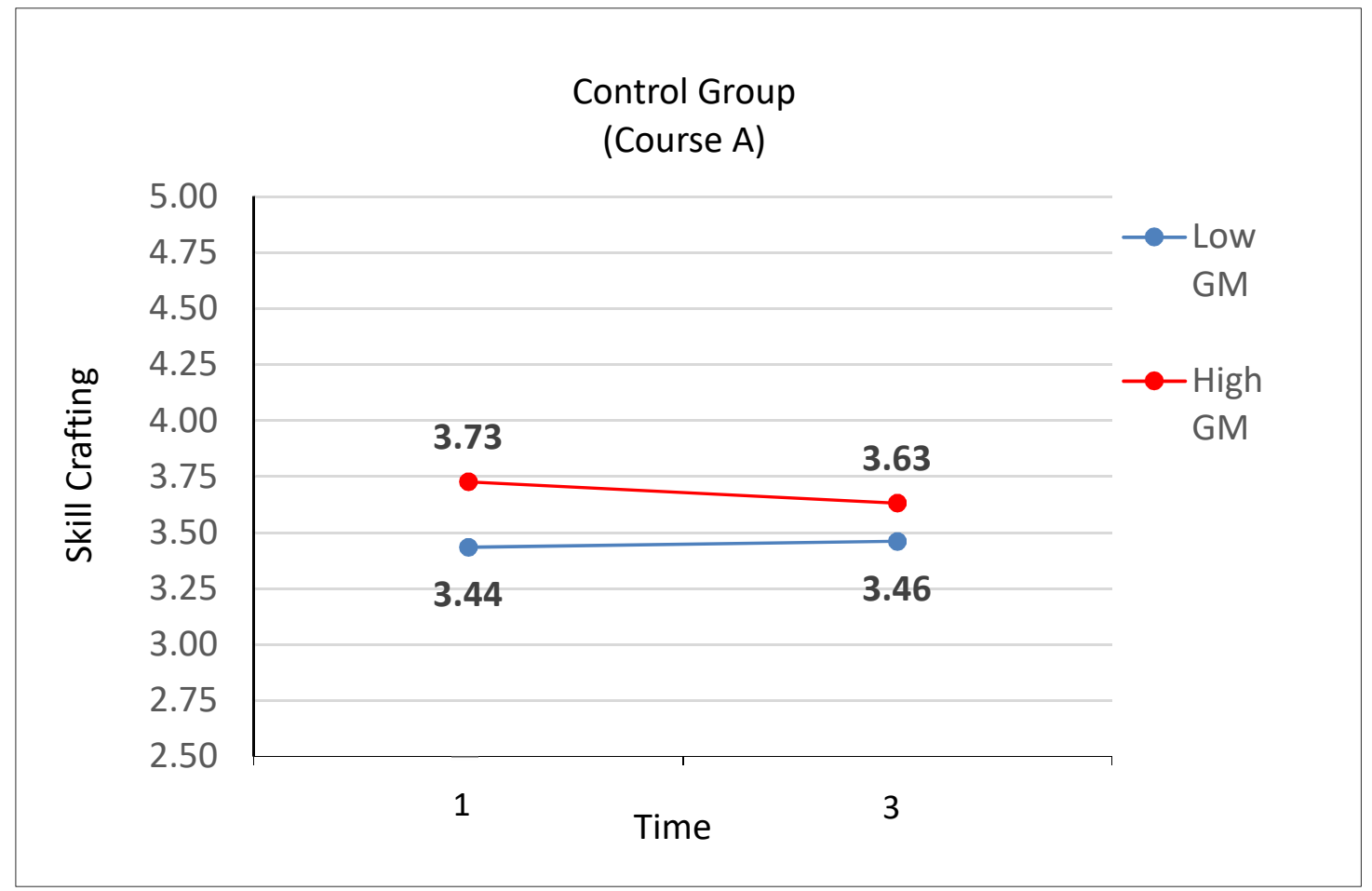

Notes: $\mathrm{GM}=$ Growth Mindset 
Figure 10

Moderation effect of a Growth Mindset on Task Crafting for Course A

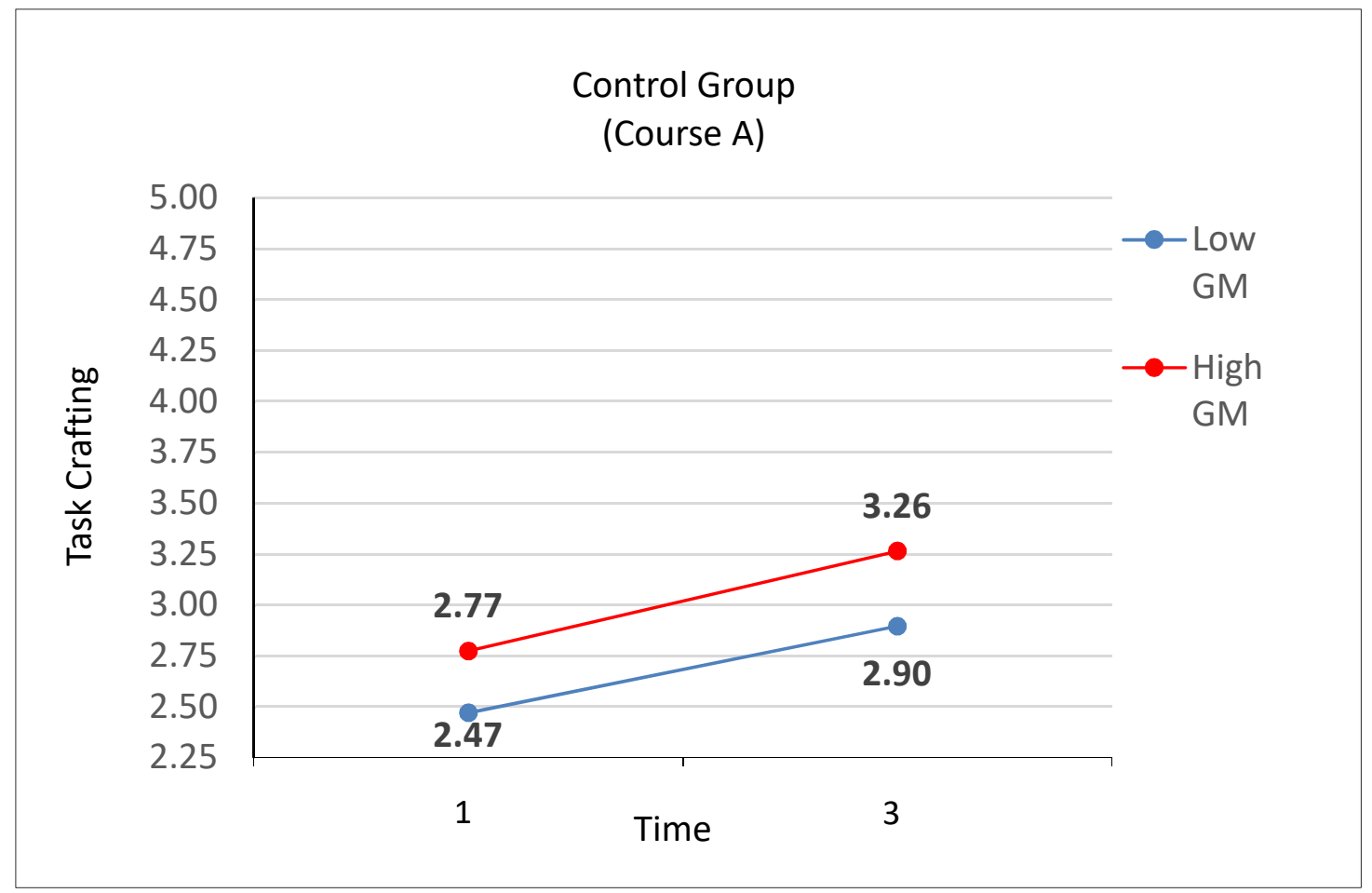

Notes: $\mathrm{GM}=$ Growth Mindset 
Figure 11

Moderation effect of a Growth Mindset on Relational Crafting for Course A

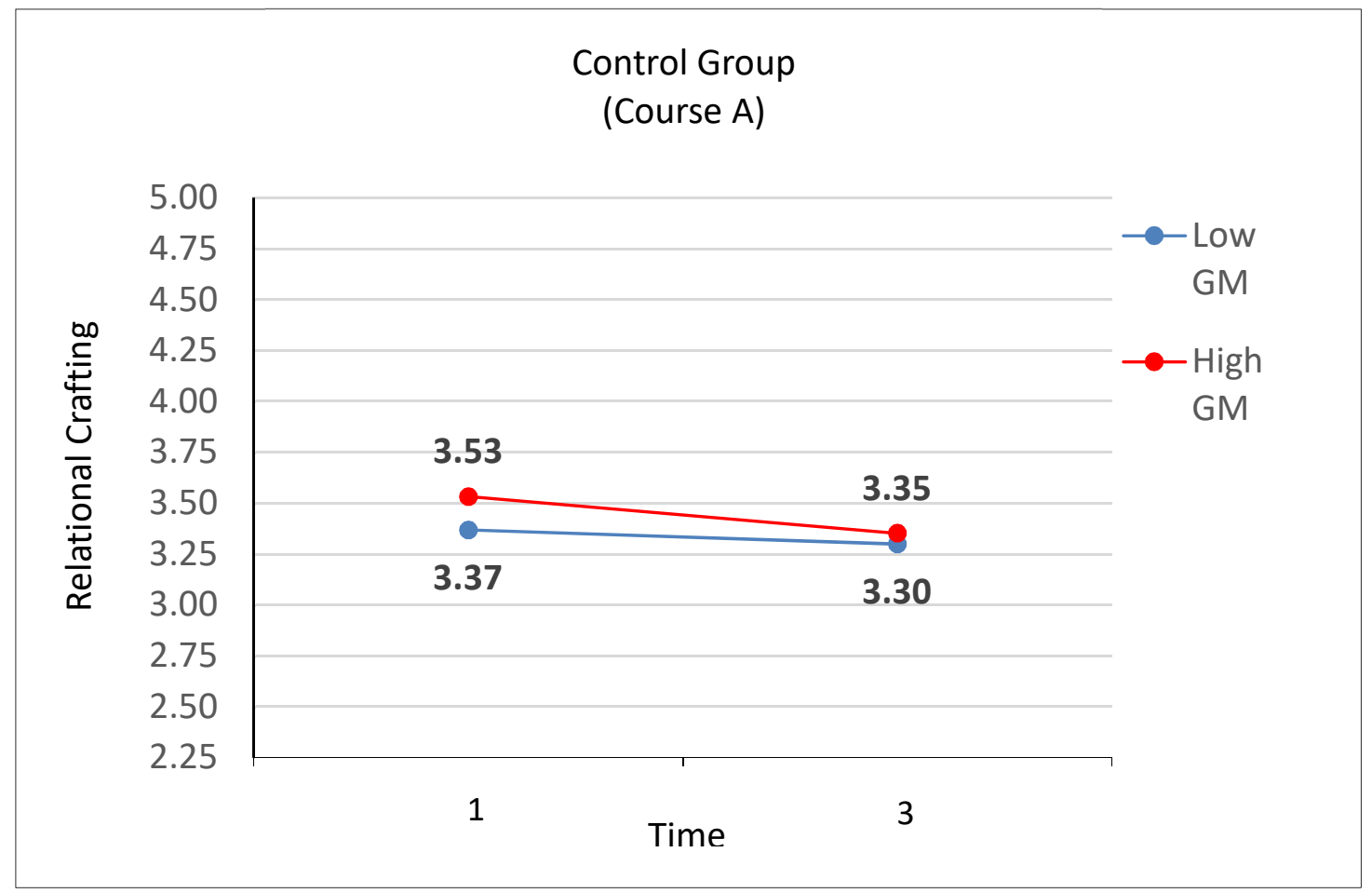

Notes: $\mathrm{GM}=$ Growth Mindset 
Appendix A

Study Measures

\begin{tabular}{|c|c|c|c|}
\hline Measure & Study Item & Response Options & Scale \\
\hline \multirow{4}{*}{$\begin{array}{l}\text { Relationship } \\
\text { Crafting }\end{array}$} & I actively seek to meet new people. & \multirow{16}{*}{$\begin{array}{l}\text { 5-point Likert Scale Frequency } \\
\text { (Never, Once per Month, } \\
\text { Twice per Month, Once or } \\
\text { Twice per Week, Every day) }\end{array}$} & \multirow{16}{*}{$\begin{array}{l}\text { Job } \\
\text { Crafting } \\
\text { Scale } \\
\text { (adapted } \\
\text { from } \\
\text { Bindl et. } \\
\text { al., 2019) }\end{array}$} \\
\hline & I make efforts to get to know other people better. & & \\
\hline & $\begin{array}{l}\text { I interact with other people, regardless of how well I know } \\
\text { them. }\end{array}$ & & \\
\hline & I spend time with a wide variety of people. & & \\
\hline \multirow[t]{4}{*}{ Skill Crafting } & I actively try to develop wider capabilities in my role. & & \\
\hline & $\begin{array}{l}\text { I try to learn new things that go beyond my core skills of } \\
\text { expertise. }\end{array}$ & & \\
\hline & I actively explore new skills. & & \\
\hline & I seek out opportunities for extending my overall skills. & & \\
\hline \multirow[t]{4}{*}{ Task Crafting } & I actively take on more tasks. & & \\
\hline & $\begin{array}{l}\text { I add complexity to my tasks by changing their structure or } \\
\text { sequence. }\end{array}$ & & \\
\hline & I change my tasks so that they were more challenging. & & \\
\hline & I increase the number of difficult decisions I make. & & \\
\hline \multirow[t]{4}{*}{$\begin{array}{l}\text { Cognitive } \\
\text { Crafting }\end{array}$} & $\begin{array}{l}\text { I try to think of my role as a whole, rather than as separate } \\
\text { tasks. }\end{array}$ & & \\
\hline & $\begin{array}{l}\text { I think about how my role contributes to the } \\
\text { organization's/university's goals. }\end{array}$ & & \\
\hline & I think about new ways of viewing my overall role. & & \\
\hline & $\begin{array}{l}\text { I think about ways in which my role as a whole contributes to } \\
\text { society. }\end{array}$ & & \\
\hline
\end{tabular}




\begin{tabular}{|c|c|c|c|}
\hline \multirow[t]{8}{*}{ Mindset } & $\begin{array}{l}\text { You have a certain amount of intelligence, and you can't really } \\
\text { do much to change it. }\end{array}$ & \multirow{8}{*}{$\begin{array}{l}\text { 7-point Likert Scale } \\
\text { Agreement (Strongly disagree, } \\
\text { Disagree, Slightly Disagree, } \\
\text { Neutral, Slightly Agree, Agree } \\
\text { and Strongly Agree) }\end{array}$} & \multirow{8}{*}{$\begin{array}{l}\text { Implicit } \\
\text { Theories of } \\
\text { Intelligence } \\
\text { Scale } \\
\text { (Dweck, } \\
2000 \text { ) }\end{array}$} \\
\hline & $\begin{array}{l}\text { Your intelligence is something about you that you can't change } \\
\text { very much. }\end{array}$ & & \\
\hline & $\begin{array}{l}\text { No matter who you are, you can significantly change your } \\
\text { intelligence level. }\end{array}$ & & \\
\hline & To be honest, you can't really change how intelligent you are. & & \\
\hline & You can always substantially change how intelligent you are. & & \\
\hline & $\begin{array}{l}\text { You can learn new things, but you can't really change your } \\
\text { basic intelligence. }\end{array}$ & & \\
\hline & $\begin{array}{l}\text { No matter how much intelligence you have, you can always } \\
\text { change it quite a bit. }\end{array}$ & & \\
\hline & $\begin{array}{l}\text { You can change even your basic intelligence level } \\
\text { considerably. }\end{array}$ & & \\
\hline $\begin{array}{l}\text { Manipulation } \\
\text { Check }\end{array}$ & $\begin{array}{l}\text { The lecture and activity made me think about my personal } \\
\text { values and beliefs. }\end{array}$ & $\begin{array}{l}\text { 7-point Likert Scale } \\
\text { Agreement (Strongly disagree, } \\
\text { Disagree, Slightly Disagree, } \\
\text { Neutral, Slightly Agree, Agree } \\
\text { and Strongly Agree) }\end{array}$ & $\mathrm{n} / \mathrm{a}$ \\
\hline \multirow{6}{*}{$\begin{array}{l}\text { Attitudes } \\
\text { Towards the } \\
\text { Workshop }\end{array}$} & Overall, I am satisfied with the lecture and activity. & \multirow{6}{*}{$\begin{array}{l}\text { 7-point Likert Scale } \\
\text { Agreement (Strongly disagree, } \\
\text { Disagree, Slightly Disagree, } \\
\text { Neutral, Slightly Agree, Agree } \\
\text { and Strongly Agree) }\end{array}$} & \multirow[t]{6}{*}{$\mathrm{n} / \mathrm{a}$} \\
\hline & I would recommend this lecture and activity to other students. & & \\
\hline & $\begin{array}{l}\text { The lecture and activity content were relevant to my job/student } \\
\text { role. }\end{array}$ & & \\
\hline & $\begin{array}{l}\text { I expect others at work/school to support me in pursuing my } \\
\text { action plan. }\end{array}$ & & \\
\hline & I am motivated to achieve the goals listed in my action plan. & & \\
\hline & I am confident in my ability to execute the actions I planned. & & \\
\hline $\begin{array}{l}\text { Action Plan } \\
\text { Success }\end{array}$ & I met all the goals listed in my Action Plan. & $\begin{array}{l}\text { 7-point Likert Scale } \\
\text { Agreement (Strongly disagree, }\end{array}$ & $\mathrm{n} / \mathrm{a}$ \\
\hline
\end{tabular}




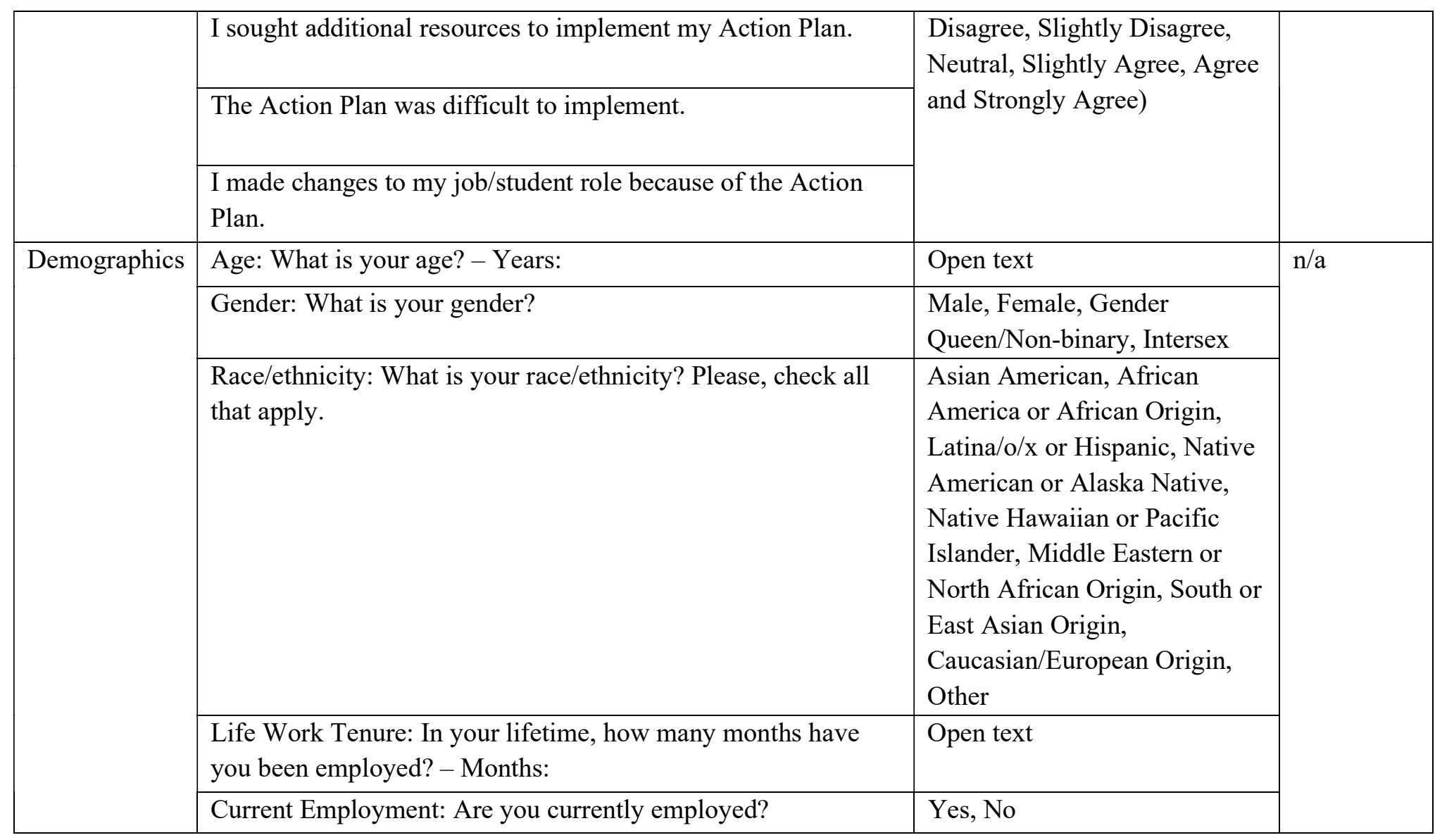




\section{Appendix B}

\section{Job Crafting Exercise Worksheet (Course B)}

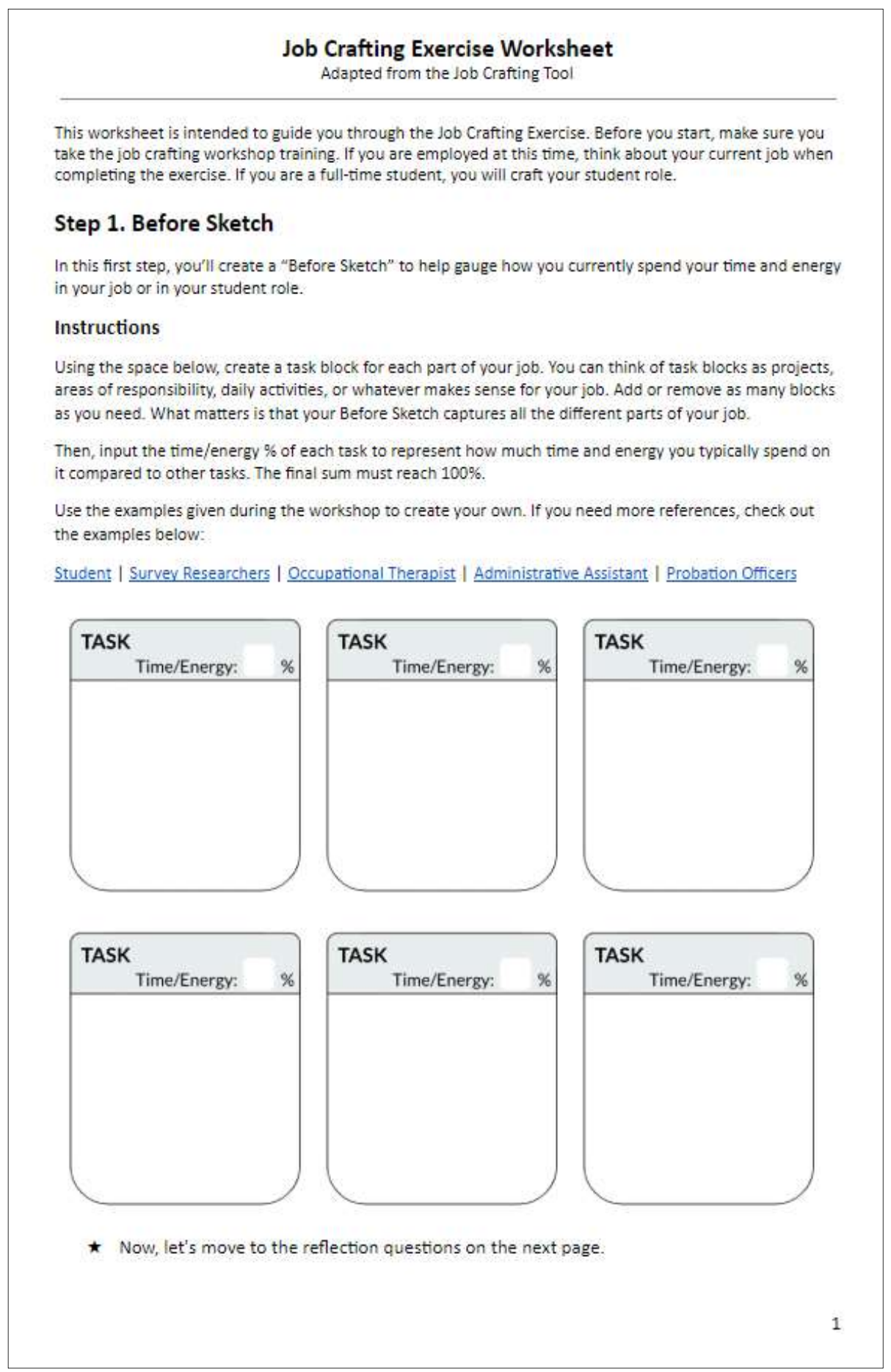




\subsection{Reflection Questions}

1. How has the division of your time and energy changed since you first started your job?

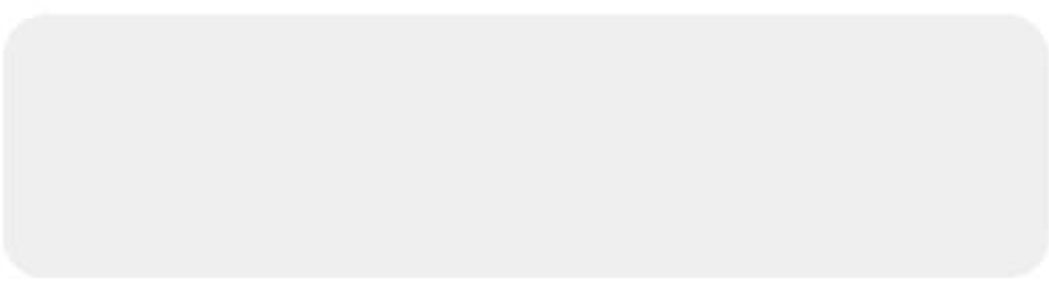

2. How do you feel about the way your time and energy is currently allocated? Why do you feel this way?

3. Does anything about your Before Sketch surprise you?

^ Now that you've mapped out all your tasks and reflected on how your job/school time has/hasn't changed so far, it's time to reflect and map out on your own values, strengths, and passions. 


\subsection{Mapping yourself}

The first step in building your After Diagram is creating symbols to represent three important aspects of yourself at work: values, strengths, and passions.

Below, select the values, strengths, and passions that best represent you. You can select two to four of each.

The aspects you select will help you decide how to craft your job in the next step.

Click here for a short description of each value, strength, or passion.

\begin{tabular}{|c|c|c|}
\hline Values & ${ }^{4} \mathrm{X}^{2}$ Strengths & Passions \\
\hline Autonomy & Judgment & Doing \\
\hline Growth & Creativity & Thinking \\
\hline Enjoyment & Wisdom & Creating \\
\hline Achievement & Expertise & Helping \\
\hline Power & Learning & Leading \\
\hline Security & Grit & Organizing \\
\hline Harmony & Focus & \\
\hline Tradition & Integrity & \\
\hline Impact & Energy & \\
\hline \multirow[t]{5}{*}{ Humanity } & Generosity & \\
\hline & Social Skill & \\
\hline & Taste & \\
\hline & Optimism & \\
\hline & Humor & \\
\hline
\end{tabular}

* Now that you've completed your Before Sketch, the next step is creating your "After Diagram," which will serve as a visual plan for how to craft your job going forward. 


\section{Step 2. After Diagram}

Use the space below to arrange your After Diagram, which should depict a more ideal (but still realistic) version of your job.

Use the examples given during the workshop to create your own. If you need more references, check out the examples below:

Student | Survey Researchers | Qccupational Therapist | Administrative Assistant | Probation Officers

\section{Instructions}

Task Crafting

- Place your values, strengths, and passions near the tasks they fit. You can add more than one symbol for the same value, strength, or passion. If you think it's feasible, feel free to add desirable tasks or drop undesirable tasks altogether.

- Change the $\%$ of time and energy to better represent how much energy you would like to spend on each task going forward. Think about how well it helps you fulfill your values, utilize your strengths or pursue your passions.

- To craft the way you perform a task to better suit you, note the desired change in parentheses after the task title.

Relational Crafting

- For each task, note any relational crafting you'd like to do. Consider the individuals and groups that may be involved with or may benefit from your work in the task.

- Think creatively about how you could craft these interactions or relationships to better suit your values, strengths, and passions.

- Write "N/A" if relational crafting is not relevant to the task.

Cognitive Crafting

- Once you finalize your task blocks, add "role frames" to craft how you see the purpose of your work. Role frames are personally meaningful labels for what a bundle of tasks accomplishes together and should represent the role(s) you would like to play in your work/school.

- You can add one large role frame around your whole job, or arrange your tasks into two or three smaller role frames.

- Do your best to place all your tasks, values, strengths, and passions in a role frame. But don't worry if some elements are not in a role frame. 


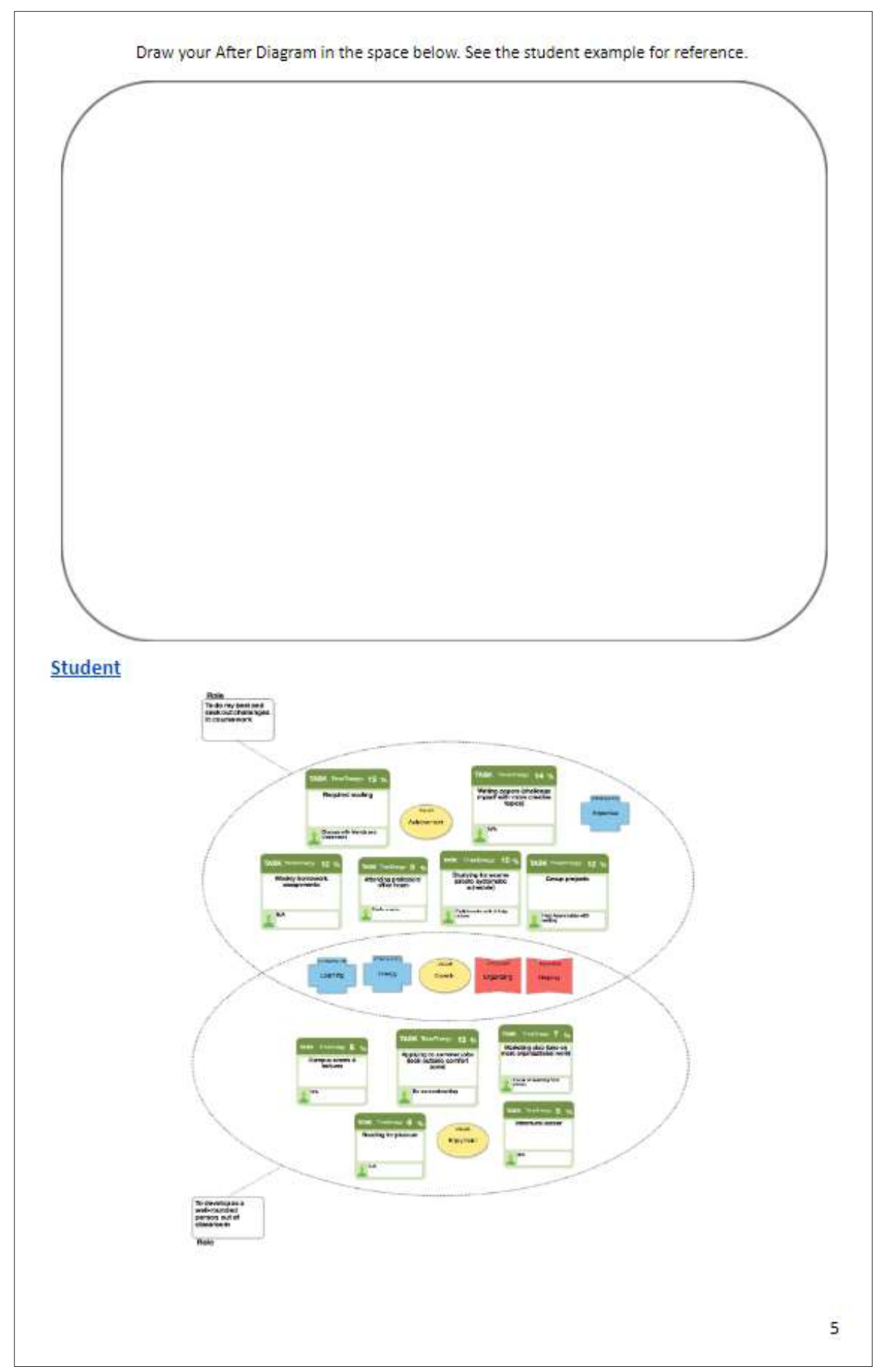




\section{Appendix}

Back to 1.3 Mapping vourself

\section{Values}

Autonomy: being independent and in control of your own work life

Growth: experiencing stimulation, novelty and challenge

Enjoyment: having fun and feeling satisfied

Achievement: earning success and respect through accomplishments

Power: attaining influence over others

Security: preserving what you like and maintaining stability

Harmony: getting along well with others

Tradition: devoting vourself to an established set of customs and ideals

Impact: helping and making meaningful connections with others

Humanity: caring for the world at large

\section{Strengths}

Judgment: making smart and informed decisions

Creativity: originality, having novel and useful ideas

Wisdom: seeing the big picture, giving helpful advice

Expertise: valuable skill or knowledge

Learning: ability to gain new skills and knowledge

Grit: persistence, overcoming adversity to reach goals

Focus: self-control, attention to detail, discipline

Integrity: being authentic and honest

Energy: working with enthusiasm and vigor

Generosity: compassion, kindness, altruism

Social Skill: understanding people, interacting well with others

Taste: recognizing aesthetic appeal and beauty in the world

Optimism: Hope about the future

Humor: making others smile/laugh, being lighthearted

\section{Passions}

Doing: working with tangible things rather than ideas

Thinking: investigating, discovering, solving problems

Creating: generating new ideas, designs, and concepts

Helping: assisting others, building relationships, sharing resources

Leading: guiding and inspiring others

Organizing: coordinating data, information, and details 


\section{Appendix C}

Job Crafting Action Plan Workshop Assignment (Course B)

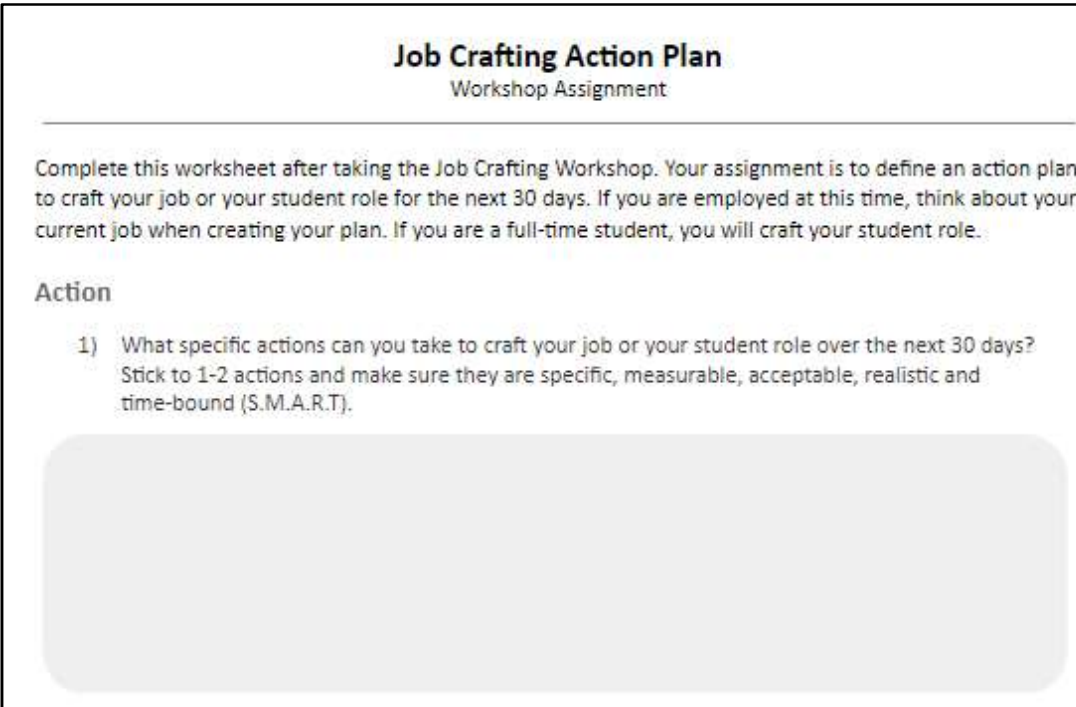

Relationships

2) What three specific people might be able to help to craft your job or your student role? How and when might you ask each of these people for help?

Challenges

3) What will be some of the main challenges or barriers involved in crafting your job or your student role? What strategies might help you avoid or overcome these challenges or barriers?

3.o. Moin chollenges or borriers: 


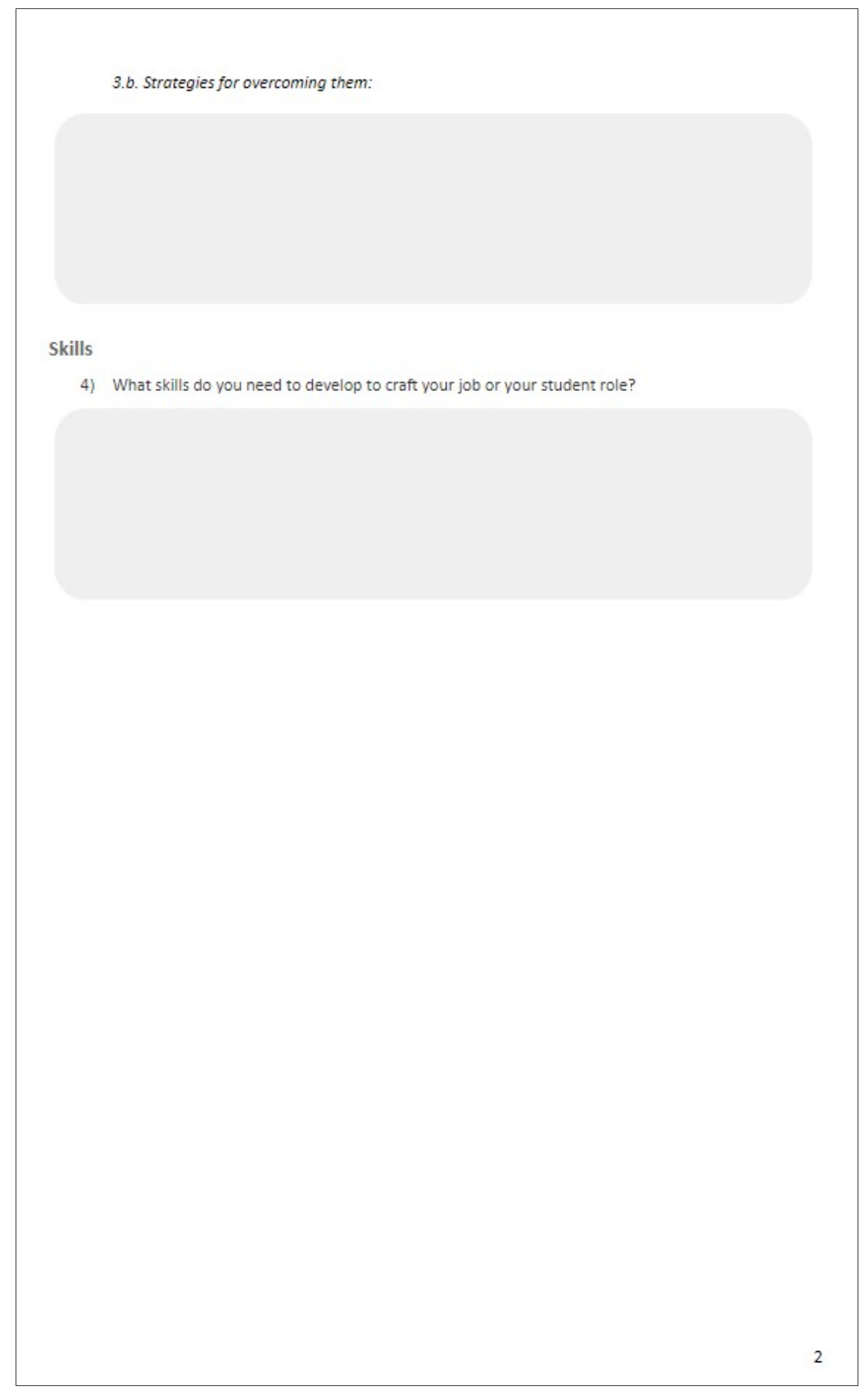


Appendix D

Job Crafting Action Plan Video Assignment (Course A)

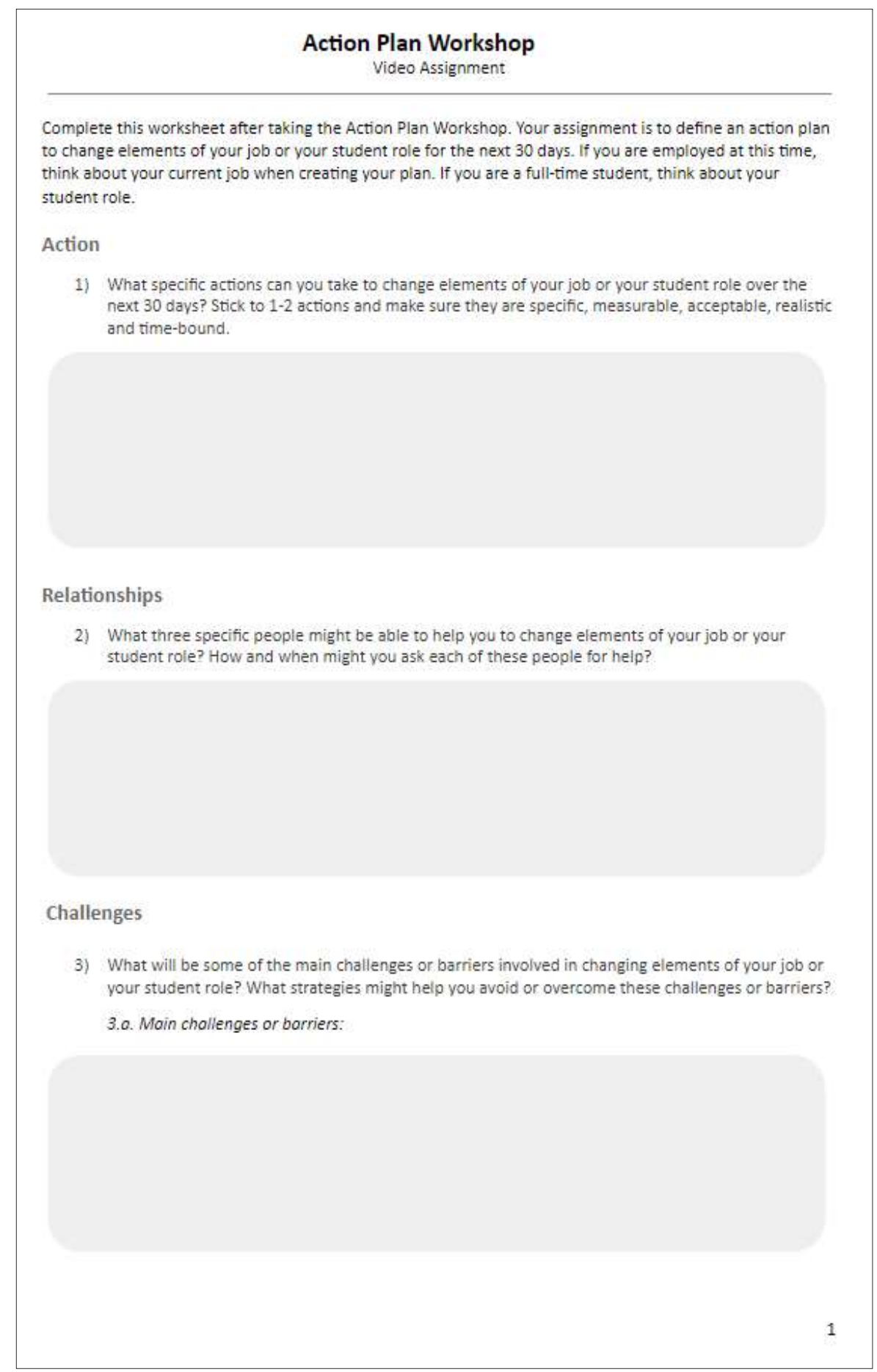


3.b. Strategies for overcoming them:

Skills

4) What skills do you need to develop so you can change elements of your job or your student role? 